\title{
Pepper Bacterial Spot Control by Bacillus velezensis: Bioprocess Solution
}

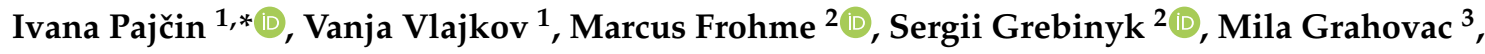 \\ Marija Mojićević ${ }^{4}$ and Jovana Grahovac ${ }^{1, *}$ \\ 1 Faculty of Technology, University of Novi Sad, Bulevar cara Lazara 1, 21000 Novi Sad, Serbia; \\ vanja.vlajkov@uns.ac.rs \\ 2 Technical University of Applied Sciences Wildau, Hochschulring 1, 15745 Wildau, Germany; \\ marcus.frohme@th-wildau.de (M.F.); sergii.grebinyk@th-wildau.de (S.G.) \\ 3 Faculty of Agriculture, University of Novi Sad, Trg Dositeja Obradovića 8, 21000 Novi Sad, Serbia; \\ mila@polj.uns.ac.rs \\ 4 Institute of Molecular Genetics and Genetic Engineering (IMGGE), University of Belgrade, \\ Vojvode Stepe 444a, P. Fah 23, 11010 Belgrade, Serbia; marijamojicevic@imgge.bg.ac.rs \\ * Correspondence: paj@tf.uns.ac.rs (I.P.); johana@uns.ac.rs (J.G.); \\ Tel.: +381-21-4853723 (I.P.); +381-21-4853682 (J.G.)
}

Received: 14 August 2020; Accepted: 5 September 2020; Published: 24 September 2020 updates

\begin{abstract}
Pepper bacterial spot is one of the most severe plant diseases in terms of infection persistence and economic losses when it comes to fresh pepper fruits used in nutrition and industrial processing. In this study, Bacillus velezensis IP22 isolated from fresh cheese was used as a biocontrol agent of pepper bacterial spot, whose main causal agent is the cosmopolitan pathogen Xanthomonas euvesicatoria. After optimization of the cultivation medium composition aimed at maximizing of the antimicrobial activity against $X$. euvesicatoria and validation of the optimized medium at the scale of a laboratory bioreactor, in planta tests were performed. The results have showed significant suppression of bacterial spot symptoms in pepper plants by the produced biocontrol agent, as well as reduction of disease spreading on the healthy (uninoculated) pepper leaves. Furthermore, HPLC-MS (high pressure liquid chromatography-mass spectrometry) analysis was employed to examine antimicrobial metabolites produced by B. velezensis IP22, where lipopeptides were found with similar $\mathrm{m} / \mathrm{z}$ values compared to lipopeptides from fengycin and locillomycin families. The bioprocess solution developed at the laboratory scale investigated in this study represents a promising strategy for production of pepper bacterial spot biocontrol agent based on B. velezensis IP22, a food isolate with a great perspective for application in plant protection.
\end{abstract}

Keywords: Xanthomonas euvesicatoria; biological control; biocontrol agent; medium optimization; lipopeptides; fengycin; locillomycin; HPLC-MS; bioreactor; laboratory scale

\section{Introduction}

Xanthomonas euvesicatoria is a bacterial phytopathogen and a cosmopolitan causal agent of pepper bacterial spot in countries with continental, tropical, and subtropical climate. Crop losses are usually very severe if the infection occurs at an early growth stage [1]. Defoliation as an infection consequence results in excessive sun exposure and possible burns to fruits [2]. Although these lesions are usually superficial, they still contribute to the lower market value of the fruits. The pathogen spreads mostly through the pepper seed and infected crop remains, but also by the rain and overhead irrigation [1]. $X$. euvesicatoria can survive in the soil, mostly in the rhizosphere of the non-host plant, as well as on pepper seeds for as long as 10 years [3]. Heavy rains, high air humidity, and temperature in the range 
30-35 ${ }^{\circ} \mathrm{C}$ contribute to bacterial spot spreading [4,5]. Leaf infection occurs due to phytopathogen penetration in the plant tissue through the stomata and hydatodes, while the fruit infection happens in the wounded spots, such as abrasions and insect lesions. Phytopathogen can multiply epiphytically on young plants without visible disease symptoms [6]. Bacterial spot symptoms on pepper fruits are rarely observed because young infected fruits usually fall of. If there are any symptoms, they include scab-like, raised, and whitish lesions on fruits [2]. Leaf symptoms are more severe and include water-soaked irregular-shaped spots which become brownish and necrotic, and usually are surrounded by the large chlorotic zones, causing premature defoliation [7]. Bacterial spot of pepper has been reported in many European countries, as well as in USA, South America, Australia, and several Asian countries [8]. Disease severity implies an infection ratio as high as 50-95\% [9], with significant economic losses due to necessity to remove infected plants and fruits in order to prevent repeated occurrence of the infection in the same field, which also represents a significant loss for the pepper processing industry and end-consumers of fresh pepper fruits.

Good agricultural practice when it comes to pepper bacterial spot consists of the use of healthy seed and transplants, as well as elimination of infected crop remains-application of phytosanitary measures [10]. Disease suppression methods include chemical treatments using copper-based bactericides in combination with ethylene bis-dithiocarbamates, but frequent application of these preparations has led to emergence of resistant X. euvesicatoria strains [11]. Moreover, these measures are not as effective as desired, even in the case of highly susceptible strains. In some countries where application of antibiotics in agriculture is allowed, streptomycin and kasugamycin have been used for suppression of X. euvesicatoria, with increased risk of development of the pathogen's resistance [12]. Alternative strategies for bacterial spot management include application of plant resistance activators, such as acibenzolar-S-methyl [13], as well as application of biological control agents such as bacteriophages [14] and bacterial biocontrol agents [15].

When it comes to use of microorganisms or their metabolites in biological control of plant pathogens, bacteria of the genus Bacillus are the most commonly used microorganisms. Beneficial traits making them suitable for application in biological control include adaptability to different ecological conditions, short generation time, sporulation ability [16], and the ability to produce wide spectra of metabolites, such as antibiotics [17], enzymes [18], and biosurfactants [19]. Furthermore, Bacillus strains are usually well adapted to the conditions where they should be applied in the form of biopesticide, since their main habitat is soil [20]. Bacillus velezensis is one of the relatively novel species consisting of many strains with pronounced biocontrol traits after recent reclassification of strains from other closely related species based on comparative genomics [21]. Many B. velezensis strains present promising biocontrol agents due to ability to synthesize different antimicrobial metabolites, such as lipopeptides [22,23], enzymes [24], biosurfactants [25,26], and volatile organic compounds [27]. Moreover, these strains express remarkable plant and rhizosphere colonization ability, which is closely related to their plant growth-promotion capabilities [28] and induction of systemic resistance in plants [29].

However, most of the research studies are focused on isolation and screening of strains potent for biological control of different plant pathogens, as well as on determination of their mechanisms of antimicrobial and biocontrol action. Very few studies are oriented to development of biotechnological processes for production of biocontrol agents. In this study, Bacillus IP22 isolated from fresh cheese was investigated as a biocontrol agent of pepper bacterial spot caused by X. euvesicatoria strains. After optimization of the cultivation medium composition for production of biocontrol agents and validation experiment in the laboratory-scale bioreactor, the obtained cultivation broth was used for treatment of pepper plants in order to assess biocontrol activity against bacterial spot causers in planta. Furthermore, identification of Bacillus IP22 was performed using $16 \mathrm{~S}$ rDNA sequencing, while analysis of the produced antimicrobial lipopeptides in the cultivation broth was carried out by HPLC-MS (high pressure liquid chromatography-mass spectrometry). 


\section{Materials and Methods}

\subsection{Microorganisms}

Bacillus IP22 was isolated from fresh cheese and identified by $16 \mathrm{~S}$ rDNA sequencing and kept on nutrient agar (HiMedia Laboratories, Mumbai, India) slant. Phytopathogenic Xanthomonas strains were isolated from diseased pepper plants with symptoms of bacterial spot. The pepper leaves were collected at several locations in the cadastral municipality Pivnice, Serbia. Xanthomonas isolates were kept on YMA (yeast maltose agar) slants containing $15 \mathrm{~g} / \mathrm{L}$ of glucose, $5 \mathrm{~g} / \mathrm{L}$ of peptone, $3 \mathrm{~g} / \mathrm{L}$ of malt extract, $3 \mathrm{~g} / \mathrm{L}$ of yeast extract and $20 \mathrm{~g} / \mathrm{L}$ of agar. The isolates were identified by the PCR (polymerase chain reaction) method using species-specific primers (XeF and XeR) [30]. All microorganisms were subcultured on previously defined media and incubated during $48 \mathrm{~h}$ at $28^{\circ} \mathrm{C}$ for Bacillus sp. and $26^{\circ} \mathrm{C}$ for Xanthomonas spp. in order to regain physiological activity prior to further utilization.

\section{2. $16 S$ rDNA Sequencing and Identification of Bacillus IP22}

Bacillus IP22 was cultured in $20 \mathrm{~mL}$ of tryptone soya broth medium (Difco Laboratories, Detroit, MI, USA) for $96 \mathrm{~h}$ with shaking at $30^{\circ} \mathrm{C}$. Cells were harvested by centrifugation (15 min, $\left.5000 \mathrm{rpm}\right)$ and biomass precipitate was resuspended in the solution for cell lysis $(10 \mathrm{~mL})$ containing sucrose (0.3 M), EDTA (25 mM), Tris- $\mathrm{HCl}(25 \mathrm{mM})$, RNase (2 U), whose $\mathrm{pH}$ value was set to 7.5. Incubation of bacterial suspension with lysozyme $(10 \mathrm{mg})$ was performed at $37^{\circ} \mathrm{C}$ for $30 \mathrm{~min}$. After addition of proteinase K ( $5 \mathrm{mg}$, Sigma Aldrich, St. Louis, MO, USA) and $1 \mathrm{~mL}$ of $10 \%(w / v)$ SDS, incubation was carried out at $55{ }^{\circ} \mathrm{C}$ for $90 \mathrm{~min}$. Afterwards, $15 \mathrm{~mL}$ of chloroform and $3.6 \mathrm{~mL}$ of $5 \mathrm{M} \mathrm{NaCl}$ were added with end-over-end rotation $(6 \mathrm{rpm})$ for $20 \mathrm{~min}$. Cell debris were removed by centrifugation (20 $\mathrm{min}$, $5000 \mathrm{rpm})$. Precipitation of DNA from the supernatant was performed using isopropanol $(1: 1, v / v)$. DNA precipitate was rinsed with $70 \%(v / v)$ ethanol $(1 \mathrm{~mL})$, air dried, and dissolved in a buffer $(10 \mathrm{mM}$ Tris-HCl, $10 \mathrm{mM}$ EDTA, pH 7.4), pre-warmed at $60^{\circ} \mathrm{C}$ [31].

The $16 \mathrm{~S}$ rDNA sequence was amplified from genomic DNA using universal bacterial primers 27F (5'-AGAGTTTGATCCTGGCTCAG-3') and 1492R (5'-GGTTACCTTGTTACGACTT-3') [32]. PCR amplification was performed in 2720 Thermal Cycler (Applied Biosystems, Thermo Fisher Scientific, Waltham, MA, USA) using FASTA Gene TAQ PCR kit following the manufacturer's protocol. PCR products were purified using a PCR purification kit (Qiagen, Hilden, Germany). Sequencing was performed with a BigDye ${ }^{\mathrm{TM}}$ Terminator v3.1 Cycle Sequencing kit (Applied Biosystems, Thermo Fisher Scientific, Waltham, MA, USA) on the Applied Biosystems 3130 Genetic Analyzer (Applied Biosystems, Thermo Fisher Scientific, Waltham, MA, USA). 16S rDNA sequences were identified using BLASTN program. Evolutionary analyses were conducted in MEGA7 [33]. 16S rDNA sequence of Bacillus IP22 has been deposited in the GenBank repository under accession number MT883432.

\subsection{PCR Identification of Xanthomonas spp.}

Xanthomonas spp. were identified using PCR according to the procedure given by Moretti et al. [30] using the species-specific primers for X. euvesicatoria - XeF (5'-CTGGGAAACTCATTCGCAGT-3') and XeR (5' - TTGTGGCGCTCTTATTTCCT-3'). Two referent isolates were used as positive controls (X. euvesicatoria 5 and X. euvesicatoria ref 1 ). These referent isolates were obtained from the culture collection of the Laboratory for seed testing of the Institute of Field and Vegetable Crops (Novi Sad, Serbia). DNA extraction from the tested and referent isolates, PCR reaction, and visualization of the obtained PCR products took place at the same laboratory. Pathogenic isolates were grown on nutrient agar (HiMedia, Mumbai, India; $26^{\circ} \mathrm{C}, 24 \mathrm{~h}$ ) and a single colony for each isolate was picked and suspended in sterile distilled water $(100 \mu \mathrm{L})$ in microtubes. Sterile distilled water was used as negative control. Cell lysis was performed according to the following procedure: heating at $95^{\circ} \mathrm{C}$ for $15 \mathrm{~min}$, cooling on ice, and centrifugation in order to separate DNA (11,000 rpm, $5 \mathrm{~min})$. 
PCR mixture $(25 \mu \mathrm{L})$ consisted of $12.5 \mu \mathrm{L}$ of $2 \times$ MMix (Eppendorf, Hamburg, Germany), $0.5 \mu \mathrm{L}$ of $10 \mu \mathrm{M}$ Forward Primer, $0.5 \mu \mathrm{L}$ of $10 \mu \mathrm{M}$ Reverse Primer, $2.0 \mu \mathrm{L}$ of template DNA, and $9.5 \mu \mathrm{L}$ of nuclease-free water. PCR reaction conditions are described in Table S1.

The obtained PCR products $(10 \mu \mathrm{L})$ were separated using gel-electrophoresis on agarose gel $(1.5 \% w / v)$ in 1xTBE (Tris-borate-EDTA) buffer (30 min, constant voltage of $100 \mathrm{~V}$, maximal current of $5 \mathrm{~V} / \mathrm{cm}$ ). Appearance of $208 \mathrm{bp}$-fragments during observation by UV transluminator was considered as a positive reaction for identification of the pathogens as members of the X. euvesicatoria species.

\subsection{Modeling and Optimization of Cultivation Medium Composition}

Optimization of medium composition for cultivation of the producing microorganism Bacillus IP22 was performed to determine optimal content of the following nutrients: glycerol as carbon source, yeast extract as organic nitrogen source, $\left(\mathrm{NH}_{4}\right)_{2} \mathrm{SO}_{4}$ as inorganic nitrogen source, and $\mathrm{K}_{2} \mathrm{HPO}_{4}$ as phosphorus source. Cultivation media were prepared according to the Box-Behnken $3^{4}$ experimental plan (Table S2), where four independent variables were varied at three levels: glycerol concentration 10-35-60 g/L, yeast extract concentration 0-2.5-5 g/L, $\left(\mathrm{NH}_{4}\right)_{2} \mathrm{SO}_{4}$ concentration 0-1.5-3 g/L, and $\mathrm{K}_{2} \mathrm{HPO}_{4}$ concentration 1-5.5-10 g/L. Besides previously mentioned nutrients, each cultivation medium has contained $\mathrm{MgSO}_{4} \cdot 7 \mathrm{H}_{2} \mathrm{O}(0.3 \mathrm{~g} / \mathrm{L})$. All media were sterilized by autoclaving $\left(121^{\circ} \mathrm{C}, 2.1 \mathrm{bar}, 20 \mathrm{~min}\right)$, while $\mathrm{pH}$ value of each medium was adjusted to $7.0 \pm 0.2$ prior to sterilization.

Inoculum was prepared using nutrient broth (HiMedia, Mumbai, India). Bacillus IP22 was cultivated on a laboratory shaker $\left(150 \mathrm{rpm}, 28^{\circ} \mathrm{C}, 48 \mathrm{~h}\right.$, spontaneous aeration). Inoculum volume was $10 \%(v / v)$ compared to cultivation medium volume $(50 \mathrm{~mL})$. After inoculation, cultivation was carried out in Erlenmayer flasks on a laboratory shaker $\left(150 \mathrm{rpm}, 28^{\circ} \mathrm{C}, 96 \mathrm{~h}\right.$, spontaneous aeration).

Dependent variables for modeling and optimization of cultivation medium composition were antimicrobial activity of cultivation broth samples (measured as inhibition zone diameter against Xanthomonas spp.) and residual content of the main nutrients (carbon, nitrogen, and phosphorus). After the end of cultivation, cultivation broth samples were used for antimicrobial activity testing using the diffusion-disc method. Residual content of nutrients (glycerol, total nitrogen, and total phosphorus) was determined using supernatants obtained after centrifugation of cultivation broth samples (10,000 rpm, 10 min; Rotina 380R, Hettich, Kirchlengern, Germany). Four second-degree polynomial equations used as models for optimization of cultivation medium composition were obtained using the Statistica 13.3 software (Dell Technologies, Round Rock, TX, USA). The same software was used to generate response surfaces graphs in order to better understand interactions between the input variables and their effect to inhibition zone diameter as the main indicator of antimicrobial activity. Optimization of the cultivation medium composition was performed using the desirability function method in the DesignExpert 8.1. software (Stat-Ease, Inc., Minneapolis, MN, USA).

\subsection{Validation Experiment}

Validation experiment was performed in the laboratory-scale bioreactor (Biostat ${ }^{\circledR}$ Aplus, Sartorius AG, Göttingen, Germany) using the cultivation medium of an optimized composition. Working volume of the bioreactor was $2 \mathrm{~L}$, while inoculum volume was $10 \%(v / v)$ compared to the cultivation medium volume. Inoculum was prepared in the same way as in the previous stage of the experiments. Cultivation of Bacillus IP22 was carried out at $28^{\circ} \mathrm{C}$, with agitation using Rushtone turbine with three impellers (agitation rate $250 \mathrm{rpm}$ ), under aerobic conditions using sterile air for aeration (aeration rate $1 \mathrm{vvm-volume} \mathrm{of} \mathrm{air/(volume} \mathrm{of} \mathrm{liquid.min)).} \mathrm{During} 96 \mathrm{~h}$ of cultivation, the following parameters were continuously measured: $\mathrm{pH}$ value and temperature. At the defined time intervals (12 h), cultivation broth was sampled from the bioreactor to determine biomass content, antimicrobial activity of the cultivation broth samples, as well as residual content of glycerol, total nitrogen, and total phosphorus. Biomass content was measured using DCW (dry cell weight) and spectrophotometric measurement of optical density of cultivation broth samples. Validation experiment was carried out in triplicate tests. 


\subsection{In Planta Experiments}

The resulting Bacillus IP22 cultivation broth obtained after the validation experiment was used to assess potential of the produced biocontrol agents in biological control of bacterial spot of pepper. Pepper plants (sort Blancina) were obtained from a commercial nursery garden (Grow rasad d.o.o., Irig, Serbia). The following variants were assessed: uninoculated and untreated control, positive control (untreated plants inoculated with Xanthomonas strains PL1 and PL2), plants treated with Bacillus IP22 cultivation broth and inoculated with Xanthomonas strains PL1 and PL2 (Table 1).

Table 1. Experimental plan in the phase of in planta antimicrobial activity assaying.

\begin{tabular}{|c|c|c|c|}
\hline Variant & Xanthomonas Isolate & Treatment & Plant Mark \\
\hline $\begin{array}{l}\text { Uninoculated untreated } \\
\text { control-negative control }\end{array}$ & - & - & 1 \\
\hline $\begin{array}{l}\text { Inoculated untreated } \\
\text { control-positive control }\end{array}$ & PL1 & - & $2 \mathrm{~A}$ \\
\hline $\begin{array}{l}\text { Inoculated untreated } \\
\text { control-positive control }\end{array}$ & PL2 & 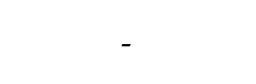 & $2 \mathrm{~B}$ \\
\hline Inoculated treated plant & PL1 & $\begin{array}{c}\text { Bacillus IP22 } \\
\text { cultivation broth }\end{array}$ & $3 \mathrm{~A}$ \\
\hline Inoculated treated plant & PL2 & $\begin{array}{c}\text { Bacillus IP22 } \\
\text { cultivation broth }\end{array}$ & $3 \mathrm{~B}$ \\
\hline
\end{tabular}

Plants were grown in pots with a diameter of $9 \mathrm{~cm}$ and height of $8 \mathrm{~cm}$, using the substrate Pindstrup Plus Blue (pH value 6.0) (Pindstrup Moseburg A/S, Ryomgaard, Denmark). Treatment with Bacillus IP22 cultivation broth was performed by dipping the plants in the cultivation broth. On the other hand, suspensions of Xanthomonas isolates were prepared using sterile saline to achieve $10^{8} \mathrm{CFU} / \mathrm{mL}$. Inoculation of plants was performed $24 \mathrm{~h}$ after the treatment using the sterile syringe (except for positive controls, where treatment with Bacillus IP22 cultivation broth was not performed). Two leaves were inoculated in each plant, with three injuries made at each leaf in the area between the leaf veins. Plants were kept in closed separate transparent containers (length $0.6 \mathrm{~m}$, width $0.4 \mathrm{~m}$, height $0.4 \mathrm{~m}$ ) at $25{ }^{\circ} \mathrm{C}$, exposed to sunlight in regular daily intervals (on average $14 \mathrm{~h} /$ day), in humid atmosphere (relative air humidity $92.0 \pm 5.0$ ) for 4 weeks. No additional supplementation of plants with nutrients was performed during the in planta experiment. Afterwards, the diameters of the emerged lesions were measured and the results were expressed as necrosis area relative to leaf area. In addition, the number of leaves with symptoms of bacterial spot per plant was recorded. Each variant contained 8 plants, and in planta assay was performed in triplicate tests.

\subsection{Analytical Methods}

\subsubsection{In Vitro Antimicrobial Activity Assaying}

Antimicrobial activity of cultivation broth samples obtained after the cultivation of Bacillus IP22 against the phytopathogenic Xanthomonas isolates PL1 and PL2 was assessed using the diffusion-disc method. Suspensions of Xanthomonas isolates were prepared using sterile saline and used for inoculation of melted and tempered $\left(50 \pm 1^{\circ} \mathrm{C}\right)$ YMA medium, which was poured in Petri dishes $(90 \mathrm{~mm})$ after the inoculation. After solidification of the medium, three paper discs (HiMedia, Mumbai, India) were placed in each Petri dish. Volume of the tested Bacillus IP22 cultivation broth samples applied to the discs was $15 \mu \mathrm{L}$. Negative control was sterile distilled water. Incubation was carried out at $26{ }^{\circ} \mathrm{C}$ for $72 \mathrm{~h}$, upon which inhibition zone diameters were measured. 


\subsubsection{Determination of Residual Content of Nutrients}

Residual content of the main nutrients (glycerol, total nitrogen, and total phosphorus) was determined using the biomass-free supernatants obtained by centrifugation of samples of Bacillus IP22 cultivation broth. Glycerol content was determined using the HPLC method. The HPLC system (Thermo Scientific Dionex UltiMate 3000 series; Thermo Fisher Scientific, Waltham, MA, USA) consists of the following components: pump HPG-3200SD/RS, autosampler WPS-3000(T)SL (10 $\mu \mathrm{L}$ injection loop), column Zorbax NH2 $(250 \mathrm{~mm} \times 4.6 \mathrm{~mm}, 5 \mu \mathrm{m}$; Agilent Technologies, Santa Clara, CA, USA), and the refractive index detector (ERC RefractoMax520, ERC GmbH, Riemerling, Germany). Mobile phase was $70 \%(v / v)$ acetonitrile. Analysis parameters were: mobile phase flow rate $1 \mathrm{~mL} / \mathrm{min}$, run time $15 \mathrm{~min}$, column temperature $30^{\circ} \mathrm{C}$, detector temperature $45^{\circ} \mathrm{C}$, injection volume $10 \mu \mathrm{L}$.

Residual content of total nitrogen was determined by the Kjeldahl method [34], while residual content of total phosphorus was determined using the spectrophotometric method with ascorbic acid [35].

\subsubsection{Determination of Bacillus IP22 Biomass Content}

Dry cell weight of Bacillus IP22 biomass was measured using the pellets obtained after centrifugation of the cultivation broth $(20 \mathrm{~mL}, 10,000 \mathrm{rpm}, 10 \mathrm{~min})$ and decanting of the supernatant. The obtained biomass pellets were dried at $105{ }^{\circ} \mathrm{C}$ until reaching the constant weight. Biomass concentration in cultivation broth was expressed in $\mathrm{g} / \mathrm{L}$ as DCW (dry cell weight) in $20 \mathrm{~mL}$ of cultivation broth.

Measurement of optical density of Bacillus IP22 cultivation broth was performed at wavelength of $600 \mathrm{~nm}$ using the spectrophotometer (UV-1800, Shimadzu, Kyoto, Japan). The blank was cultivation medium used for cultivation of Bacillus IP22 in the laboratory-scale bioreactor.

\subsubsection{HPLC-MS Analysis of the Antimicrobial Lipopeptides Produced by Bacillus IP22}

Sample used for analysis of the antimicrobial lipopeptides produced by Bacillus IP22 was the supernatant obtained after centrifugation of cultivation broth sample at the end of the validation experiment. HPLC-MS was used for lipopeptide analysis as proposed by Smyth et al. [36].

Mass spectrometry analysis after chromatographic separation was achieved with a tandem quadruple mass spectrometer LCMS-8040, equipped with an electrospray ionization (ESI) source (Shimadzu, Kyoto, Japan) coupled to a Nexera high-performance liquid chromatography (HPLC) system. HPLC separation was performed with XDB-C18 $(100 \mathrm{~mm} \times 4.6 \mathrm{~mm}, 3 \mu \mathrm{M})$ column (Agilent Technologies, Santa Clara, CA, USA). The column was thermostabilized at $40^{\circ} \mathrm{C}$. A mobile phase of $5 \mathrm{mmol} / \mathrm{L}$ ammonium acetate solution containing $0.1 \%(v / v)$ formic acid (A) and methanol (B) was used. The following linear gradient elution was used: $10 \% \mathrm{~B}$ held to $1 \mathrm{~min}$, then increased to $90 \%$ from 1 to $7 \mathrm{~min}$, then held at $90 \%$ B from 7 to $12 \mathrm{~min}$, then decreased to $10 \% \mathrm{~B}$ from 12 to $13.5 \mathrm{~min}$, and further held at $10 \% \mathrm{~B}$ until $16 \mathrm{~min}$. The flow rate was set at $0.5 \mathrm{~mL} / \mathrm{min}$. The mass spectrometer was mass-calibrated against an autotuning standard solution (a mixture of PEG, PPG, and raffinose: $m / z$ 65.05, 168.10, 256.15, 344.20, 652.40, 1004.60, and 1224.75) for LC-MS (Shimadzu, Kyoto, Japan). For mass detection, both positive and negative ionization modes were used. The technical parameters for the MS measurements were a spray capillary voltage of $3.0 \mathrm{kV}$, a detector voltage of $2.04 \mathrm{kV}$, an interface voltage of $4.5 \mathrm{kV}$, a desolvation line temperature of $250^{\circ} \mathrm{C}$, a heat block temperature of $450{ }^{\circ} \mathrm{C}$, a nebulizing gas flow rate of $3.0 \mathrm{~mL} / \mathrm{min}$, a drying gas flow rate of $15 \mathrm{~mL} / \mathrm{min}$. Acquisition was performed in the selected ion monitoring (SIM) mode with a dwell time of $0.2 \mathrm{~s}$.

\subsection{Statistical Analysis of the Experimental Data}

The experimental data obtained after the cultivation of Bacillus IP22 in the phase of modeling of cultivation medium composition were fitted using four polynomial equations of the second order for the following bioprocess responses: inhibition zone diameter, residual glycerol content, 
residual total nitrogen content, and residual total phosphorus content. Statistical analysis of the experimental data for modeling of cultivation medium composition was performed using the Statistica 13.3 software (Dell Technologies, Round Rock, TX, USA). All statistical analyses were performed at significance level of $95 \%$. Mean values and standard deviations for the experimental replications during validation experiments were calculated and plotted to monitor cultivation course using Origin 9 software (OriginLab Corporation, Northampton, MA, USA). Mean values and standard deviations for replications in the phase of in planta testing were calculated using Microsoft Excel 2010 (Microsoft Corporation, Redmond, WA, USA). Duncan's multiple range test was also performed using the results of in planta testing to establish homogenous groups of variances using the Statistica 13.3 software (Dell Technologies, Round Rock, TX, USA).

\section{Results}

\section{1. $16 S$ rDNA Sequencing and Identification of Bacillus IP22}

$16 \mathrm{~S}$ rDNA sequence alignment and phylogenetic analysis (16S ribosomal DNA sequences Database) of the selected producing microorganism have revealed closest similarity to Bacillus velezensis (100\% query coverage, $99 \%$ homology).

The Tamura-Nei model [37] and the maximum likelihood method were used to infer the evolutionary history. Figure 1 shows the phylogenetic tree with the highest log likelihood (-1378.78), while the numbers next to the branches represent the percentage of trees in which the associated taxa clustered together. Neighbor-join and BioNJ algorithms were applied to obtain initial tree(s) for the heuristic search, while the maximum composite likelihood (MCL) approach was applied to estimate the matrix of pairwise distances, followed by the selection of topology with the highest log likelihood value. The phylogenetic tree is drawn to scale, where branch lengths represent the number of substitutions per site, while six nucleotide sequences were included in the analysis. Included codon positions were 1st+2nd+3rd+Noncoding. Final dataset consisted of 661 positions, while elimination was performed on all positions which contained missing data and gaps.
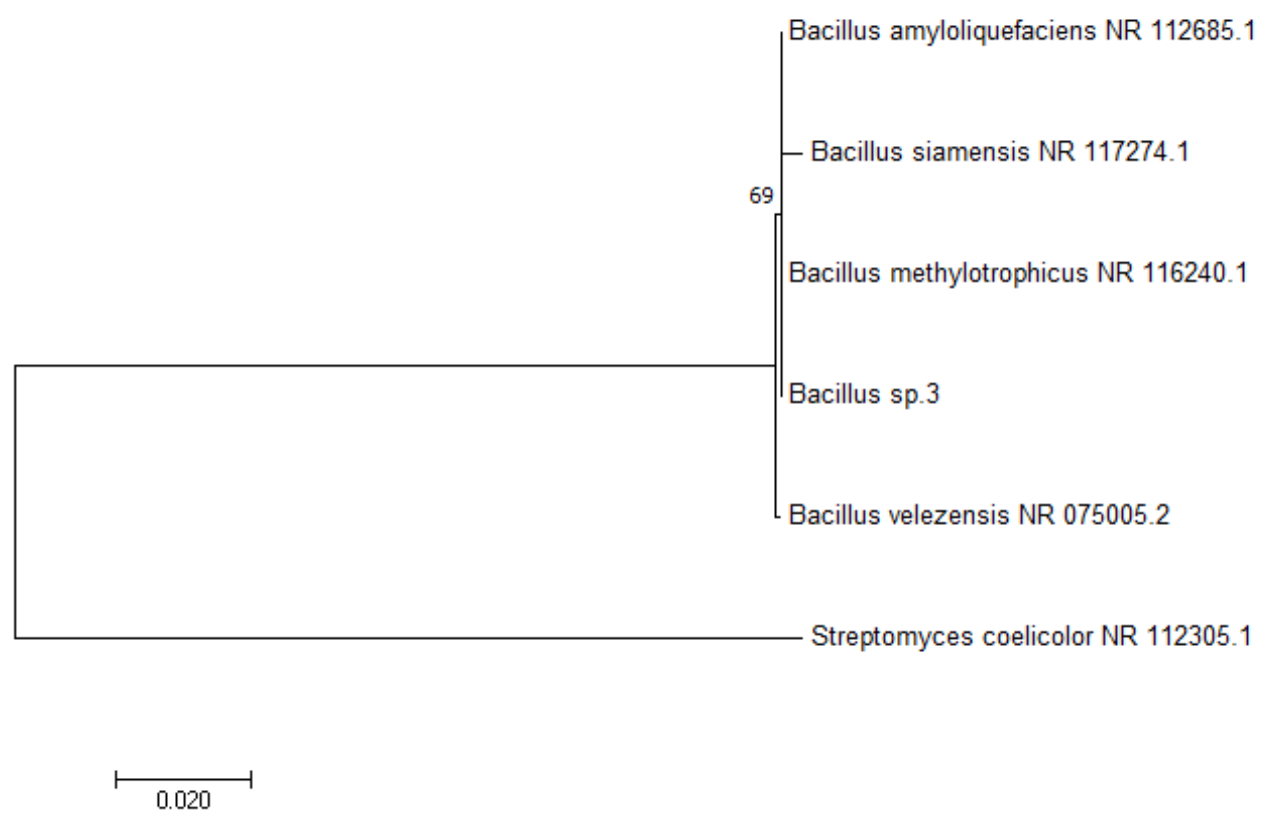

Figure 1. Molecular phylogenetic analysis of the Bacillus IP22 (in the figure marked as Bacillus sp.3) 16S rDNA sequence by the maximum likelihood method.

Based on the presented results, the producing microorganism was identified as a member of the species Bacillus velezensis. 


\subsection{PCR Identification of Xanthomonas spp.}

The results of visualization of the obtained PCR products are represented in Figure 2. PCR products with length of 208 bp obtained using species-specific primers were successfully amplified for all tested pathogenic isolates, as well as for referent $X$. euvesicatoria strains ( 5 and ref 1 ). There was no amplification of the selected DNA fragment in negative control. Based on the presented results, all pathogenic isolates from pepper leaves were identified as X. euvesicatoria strains. Isolates PL1 and PL2 were selected for further biocontrol trials.

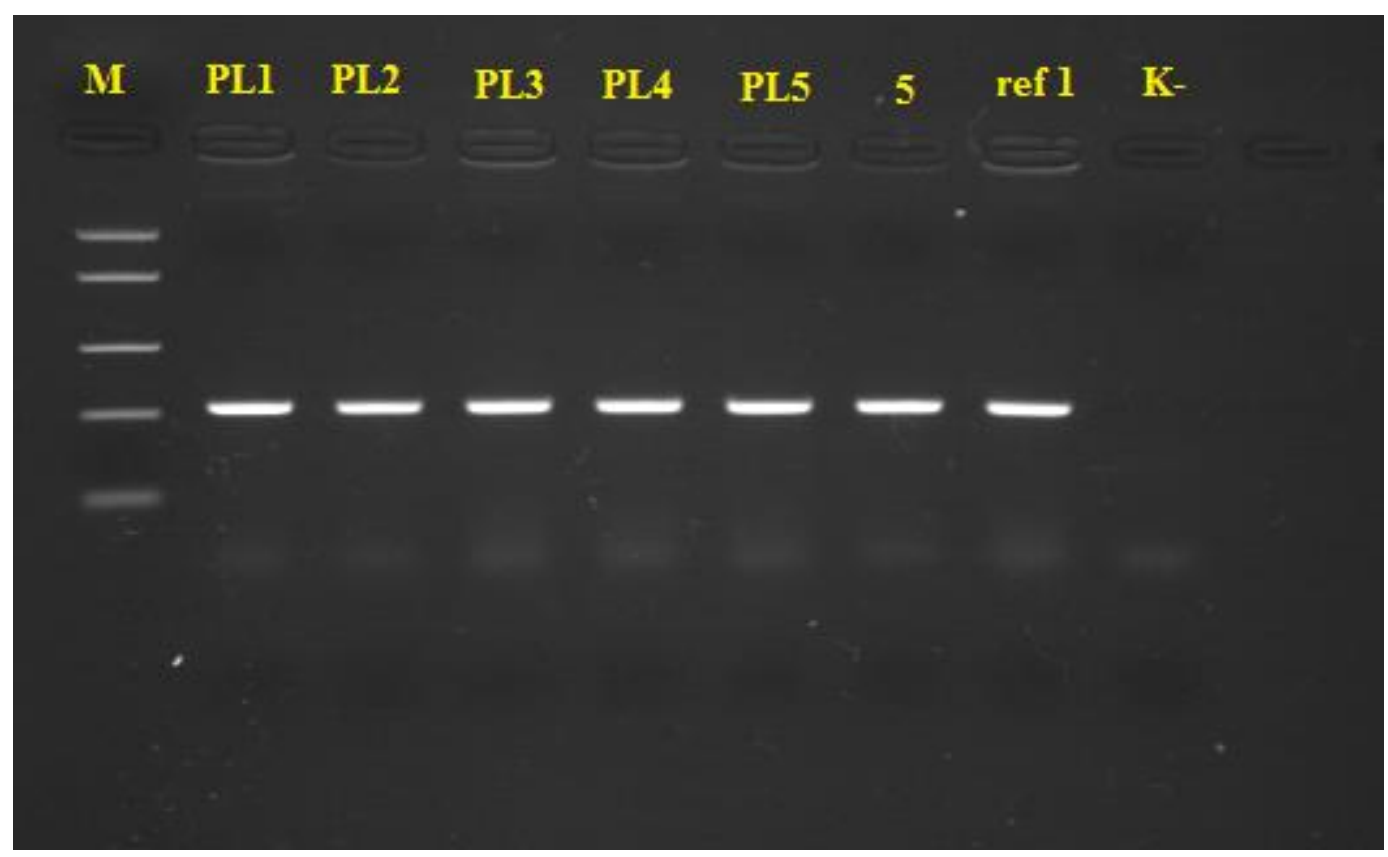

Figure 2. Visualization of the amplified PCR products in 1.5\% agarose gel during PCR identification of pathogenic Xanthomonas spp. (M-gene ruler, PL1-PL5-PCR products from phytopathogenic Xanthomonas spp., 5 and ref $1-\mathrm{PCR}$ products from referent isolates, $\mathrm{K}$-negative control)

\subsection{Modeling and Optimization of Medium Composition for Cultivation of B. velezensis IP22}

Cultivation medium used for cultivation of B. velezensis IP22, i.e., for production of biocontrol agent, has contained several nutrients (glycerol as carbon source, yeast extract as organic nitrogen source, $\left(\mathrm{NH}_{4}\right)_{2} \mathrm{SO}_{4}$ as inorganic nitrogen source, and $\mathrm{K}_{2} \mathrm{HPO}_{4}$ as phosphorus source), whose effects on antimicrobial activity of the producing strain against phytopathogenic $X$. euvesicatoria strains have been investigated. Furthermore, besides the effect on inhibition zone diameter as the main indicator of antimicrobial activity of B. velezensis IP22 cultivation broth against X. euvesicatoria, initial content of these nutrients in the medium for cultivation of $B$. velezensis IP22 was varied (Table 2) in order to investigate their effects to residual content of carbon, nitrogen, and phosphorus in the resulting cultivation broth after the cultivation of B. velezensis IP22.

For purpose of modeling, second degree polynomial equations were used to fit the experimental data. The obtained linear, quadratic, and interaction regression coefficients, as well as their statistical significance ( $p$-value less than 0.05 ), are presented using Pareto charts for the selected dependent variables-inhibition zone diameter, residual content of glycerol, residual total content of nitrogen, and residual total content of phosphorus (Figure 3). 
Table 2. ANOVA (analysis of variance) for the selected responses in the phase of modeling of medium composition for cultivation of $B$. velezensis IP22.

\begin{tabular}{ccccccc}
\hline Response & SS & DF & MS & F & $p$-Value & $\mathbf{R}^{\mathbf{2}} \mathbf{( \% )}$ \\
\hline Inhibition zone diameter $(\mathrm{mm})$ & $39076.79^{\mathrm{a}}$ & $15^{\mathrm{a}}$ & $2605.12^{\mathrm{a}}$ & \multirow{2}{*}{4127.72} & $<0.01$ & 94.94 \\
& $7.57^{\mathrm{b}}$ & $12^{\mathrm{b}}$ & $0.63^{\mathrm{b}}$ & & & \\
Residual glycerol content $(\mathrm{g} / \mathrm{L})$ & $17270.84^{\mathrm{a}}$ & $15^{\mathrm{a}}$ & $1151.39^{\mathrm{a}}$ & 63.37 & $<0.01$ & 94.89 \\
& $218.02^{\mathrm{b}}$ & $12^{\mathrm{b}}$ & $18.17^{\mathrm{b}}$ & & & \\
Residual total nitrogen content $(\mathrm{g} / \mathrm{L})$ & $27.56^{\mathrm{a}}$ & $15^{\mathrm{a}}$ & $1.84^{\mathrm{a}}$ & 191.00 & $<0.01$ & 95.68 \\
& $0.12^{\mathrm{b}}$ & $12^{\mathrm{b}}$ & $0.01^{\mathrm{b}}$ & & & \\
Residual total phosphorus content $(\mathrm{g} / \mathrm{L})$ & $89.67^{\mathrm{a}}$ & $15^{\mathrm{a}}$ & $5.98^{\mathrm{a}}$ & 32.91 & $<0.01$ & 90.39 \\
\hline
\end{tabular}

SS—sum of squares, DF-degree of freedom, MS - mean squares, $\mathrm{R}^{2}$ — coefficient of determination. ${ }^{\mathrm{a}}$ model, ${ }^{\mathrm{b}}$ residual.

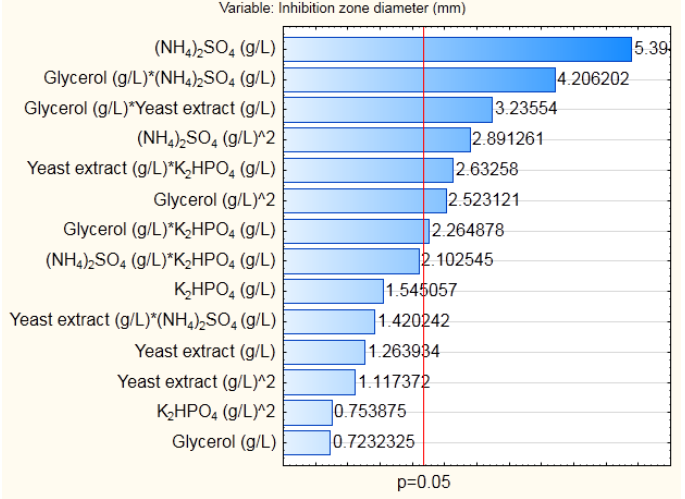

(a)

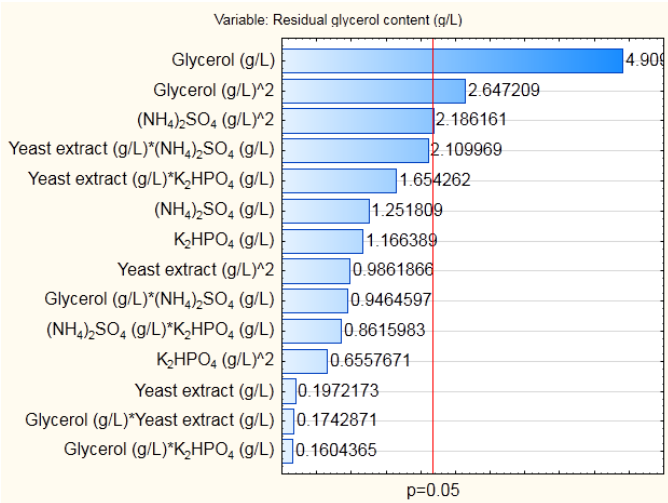

(b)

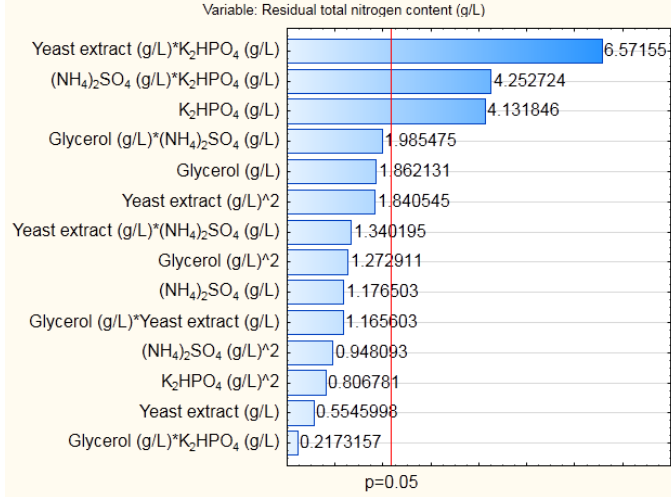

(c)

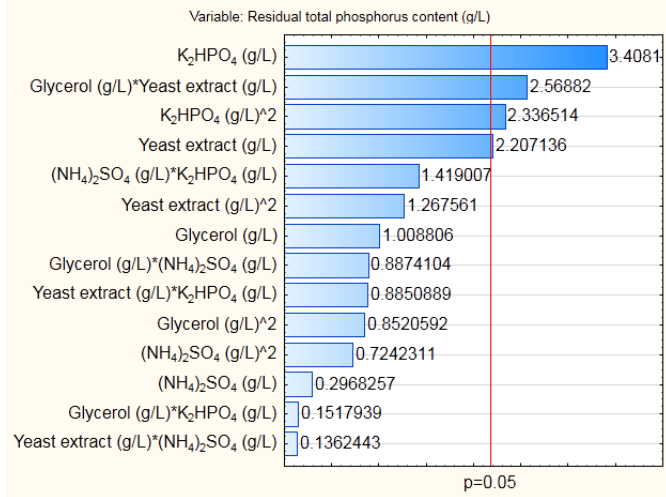

(d)

Figure 3. Pareto charts-coefficients of regression models for the selected dependent variables during modeling of medium composition for cultivation of B. velezensis IP22: (a) inhibition zone diameter, (b) residual glycerol content, (c) residual total nitrogen content, (d) residual total phosphorus content. The red line in the charts represents a limit of statistical significance ( $p$-value equal to 0.05 ) at the confidence level of $95 \%$.

Analysis of variance (ANOVA) was also performed for each model obtained for the selected outputs in order to assess whether the obtained models are statistically significant with confidence level of $95 \%$ (Table 2 ).

Considering the calculated statistical parameters for analysis of variance, it can be concluded that each model was statistically significant with confidence level of 99\%, with $p$-values lower than 0.01 . 
In order to investigate the effect of nutrients' content on inhibition zone diameter, as the dependent variable which mostly affects antimicrobial activity of $B$. velezensis IP22 against X. euvesicatoria, response surface plots (Figure 4) were generated to present the effects of two variables, while the other two remained constant at the value of central point from the Box-Behnken experimental plan (Table S2).

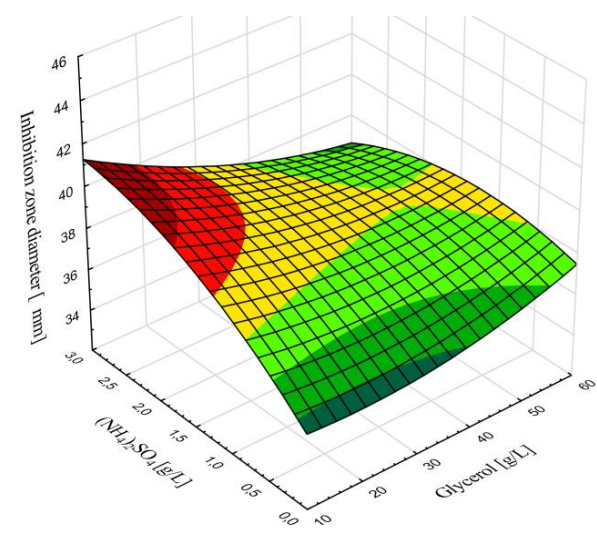

(a)

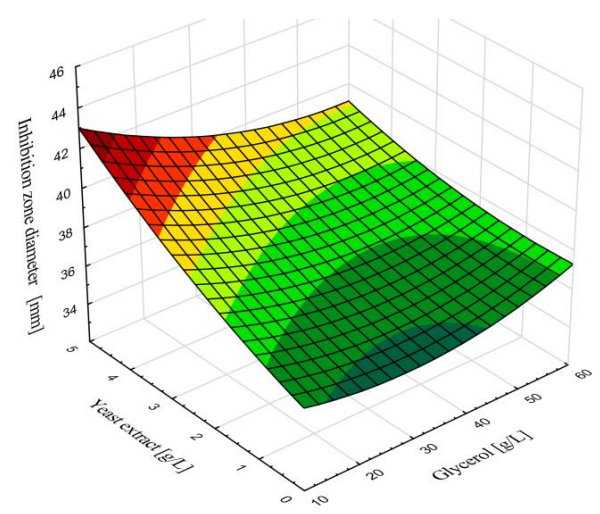

(b)

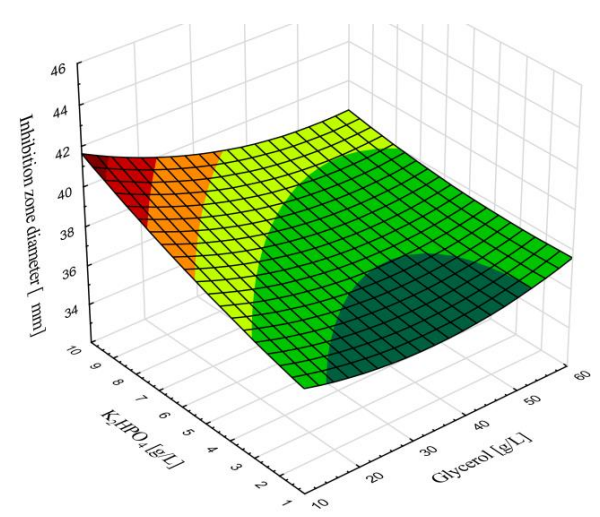

(c)

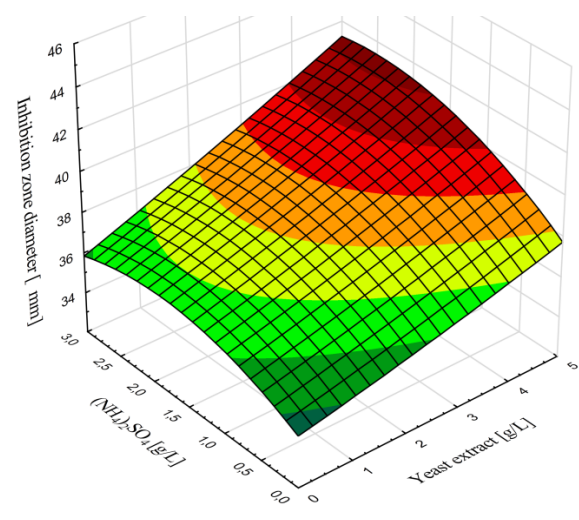

(d)

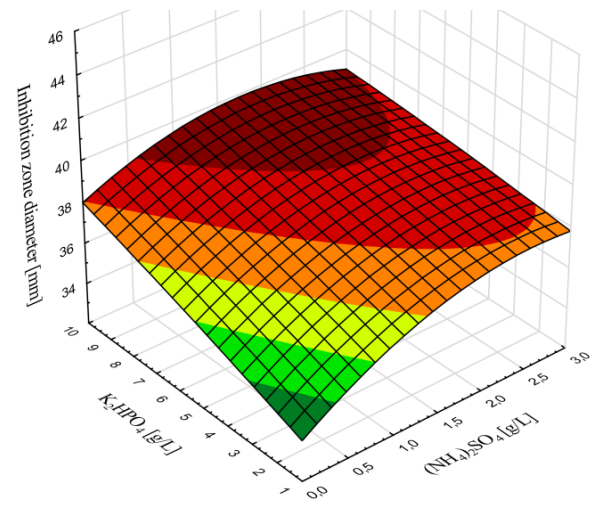

(e)

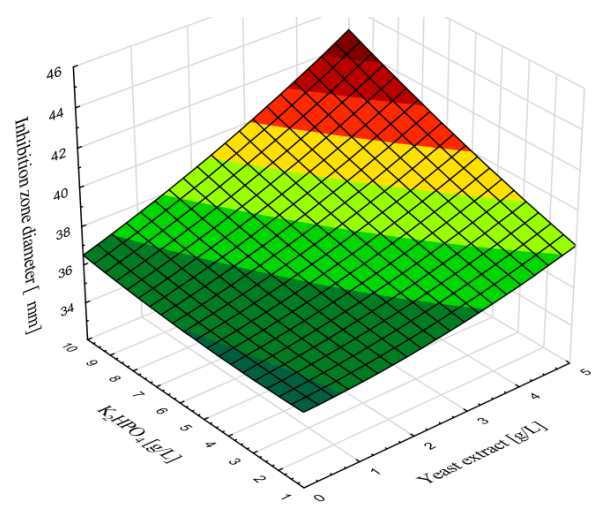

(f)

Figure 4. Response surface plots for effects of nutrients' content on inhibition zone diameter for the following combination of independent variables: (a) glycerol and $\left(\mathrm{NH}_{4}\right)_{2} \mathrm{SO}_{4}$, (b) glycerol and yeast extract, (c) glycerol and $\mathrm{K}_{2} \mathrm{HPO}_{4},(\mathbf{d})\left(\mathrm{NH}_{4}\right)_{2} \mathrm{SO}_{4}$ and yeast extract, (e) $\left(\mathrm{NH}_{4}\right)_{2} \mathrm{SO}_{4}$ and $\mathrm{K}_{2} \mathrm{HPO}_{4}$, (f) yeast extract and $\mathrm{K}_{2} \mathrm{HPO}_{4}$. 
Considering the effects of main nutrients (glycerol, yeast extract, $\left(\mathrm{NH}_{4}\right)_{2} \mathrm{SO}_{4}$, and $\mathrm{K}_{2} \mathrm{HPO}_{4}$ ), whose initial concentrations in the cultivation medium were selected as independent variables, on inhibition zone diameter, it could be concluded that maximal inhibition zone diameter against $X$. euvesicatoria is expected when using minimal concentration of glycerol (around $10 \mathrm{~g} / \mathrm{L}$ ), almost maximal concentration of yeast extract $(4.5-5 \mathrm{~g} / \mathrm{L}),\left(\left(\mathrm{NH}_{4}\right)_{2} \mathrm{SO}_{4}\right.$ in the concentration range 1-3 g/L, and almost maximal concentration of $\mathrm{K}_{2} \mathrm{HPO}_{4}(9-10 \mathrm{~g} / \mathrm{L})$. The expected maximal inhibition zone diameter is in the range $42-45 \mathrm{~mm}$ (Figure 4 ).

Optimization of the medium composition for production of biocontrol agents by $B$. velezensis IP22, in terms of initial content of the main nutrients (glycerol as carbon source, yeast extract as organic nitrogen source, $\left(\mathrm{NH}_{4}\right)_{2} \mathrm{SO}_{4}$ as inorganic nitrogen source, and $\mathrm{K}_{2} \mathrm{HPO}_{4}$ as phosphorus source), was the next step in bioprocess development. Optimization of cultivation medium composition was performed using the desirability function method, where the same importance coefficient was assigned to each independent and dependent variable, while desirability function was calculated using the DesignExpert software for the desired optimization outcomes defined as optimization aims (Table 3).

Table 3. Results of the optimization of medium composition for cultivation of B. velezensis IP22.

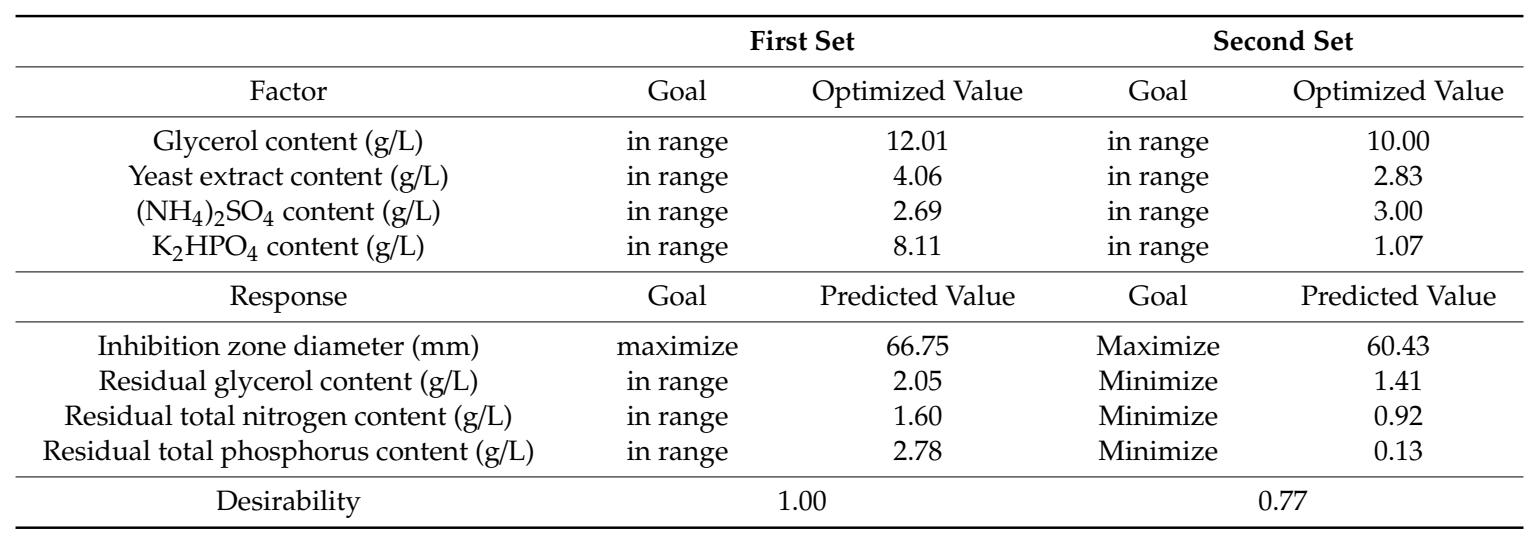

The first optimization set was aimed at maximization of antimicrobial activity of $B$. velezensis IP22 cultivation broth against X. euvesicatoria. Therefore, the goal of the first optimization set was to maximize inhibition zone diameter obtained by the antimicrobial activity testing. Optimization results have showed that maximal inhibition zone diameter of $66.75 \mathrm{~mm}$ could be obtained using the medium for cultivation of $B$. velezensis IP22 of the following composition: glycerol $12.0 \mathrm{~g} / \mathrm{L}$, yeast extract $4.0 \mathrm{~g} / \mathrm{L}$, $\left(\mathrm{NH}_{4}\right)_{2} \mathrm{SO}_{4} 2.7 \mathrm{~g} / \mathrm{L}, \mathrm{K}_{2} \mathrm{HPO}_{4} 8.1 \mathrm{~g} / \mathrm{L}$, and $\mathrm{MgSO}_{4} \cdot 7 \mathrm{H}_{2} \mathrm{O} 0.3 \mathrm{~g} / \mathrm{L}$. Furthermore, desirability function value 1 has implied complete fulfillment of the optimization goal previously set. However, since usage of cultivation medium formulated as given in the first optimization set would result in very high residual content of carbon, nitrogen, and phosphorus in the cultivation broth at the end of cultivation, one more optimization set was performed to minimize residual content of the aforementioned nutrients, simultaneously with keeping the antimicrobial activity maximized. Desirability function value of 0.77 has implied satisfying fulfillment of the optimization goals using the cultivation medium of the following composition: glycerol $10.0 \mathrm{~g} / \mathrm{L}$, yeast extract $2.8 \mathrm{~g} / \mathrm{L},\left(\mathrm{NH}_{4}\right)_{2} \mathrm{SO}_{4} 3.0(\mathrm{~g} / \mathrm{L}), \mathrm{K}_{2} \mathrm{HPO}_{4} 1.0(\mathrm{~g} / \mathrm{L})$, and $\mathrm{MgSO}_{4} \cdot 7 \mathrm{H}_{2} \mathrm{O} 0.3 \mathrm{~g} / \mathrm{L}$.

\subsection{Validation Experiment-Cultivation of B. velezensis IP22 in a Laboratory-Scale Bioreactor}

Experiment aimed at validation of the optimized medium composition for cultivation of $B$. velezensis IP22 was performed in the laboratory-scale bioreactor, as a bioprocess vessel of a larger volume (working volume of $2 \mathrm{~L}$ ). During cultivation, temperature, mixing, and aeration regulation were performed to keep constant temperature $\left(28^{\circ} \mathrm{C}\right)$, agitation rate $(250 \mathrm{rpm})$ and aeration rate $(1 \mathrm{vvm})$. Bioprocess parameters that were monitored during the cultivation were $\mathrm{pH}$ value (Figure $5 \mathrm{a}$ ) and temperature. Temperature was maintained constant $\left(28^{\circ} \mathrm{C}\right)$ during the whole bioprocess due to temperature regulation. Cultivation 
broth samples were sampled at predefined time intervals $(12 \mathrm{~h})$ in order to determine biomass content (concentration of B. velezensis IP22 biomass and optical density of the cultivation broth) and residual nutrients' content (glycerol, total nitrogen, and total phosphorus), as well as antimicrobial activity of cultivation broth samples against X. euvesicatoria. Cultivation course considering these variables is given in Figure 5. The results represent mean values and standard deviation from three cultivations performed under the similar conditions in the laboratory-scale bioreactor.

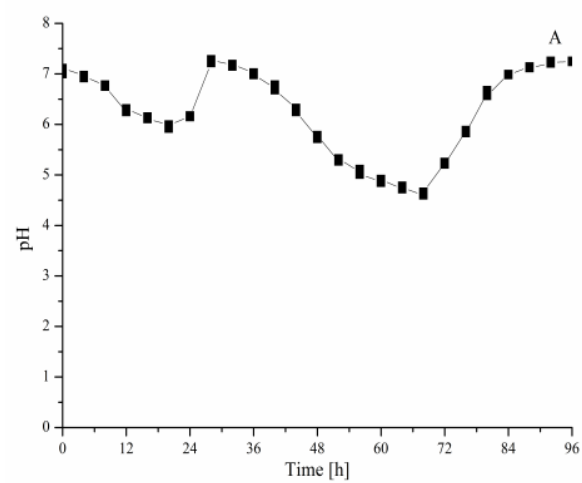

(a)

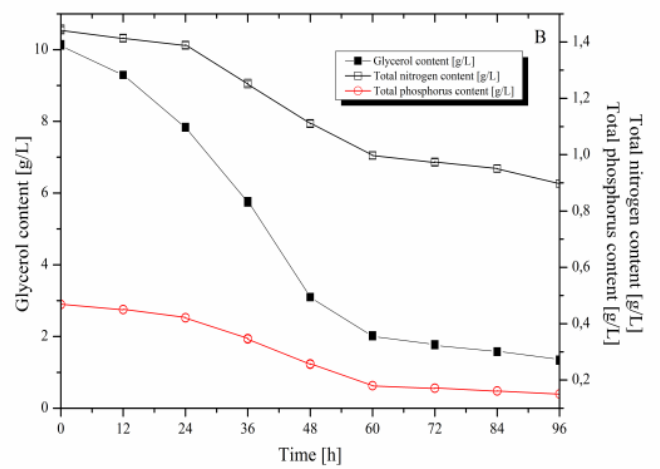

(b)

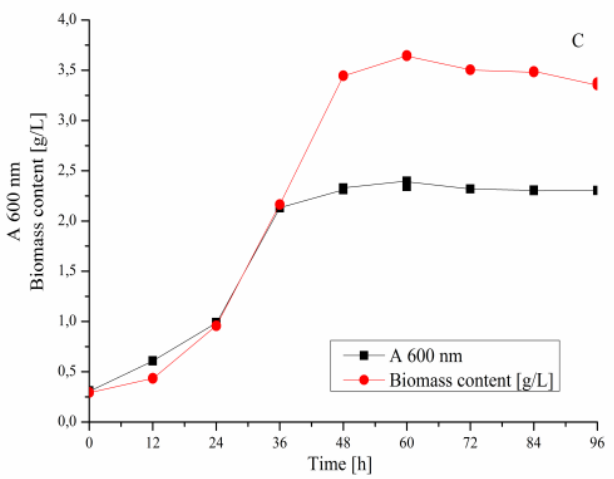

(c)

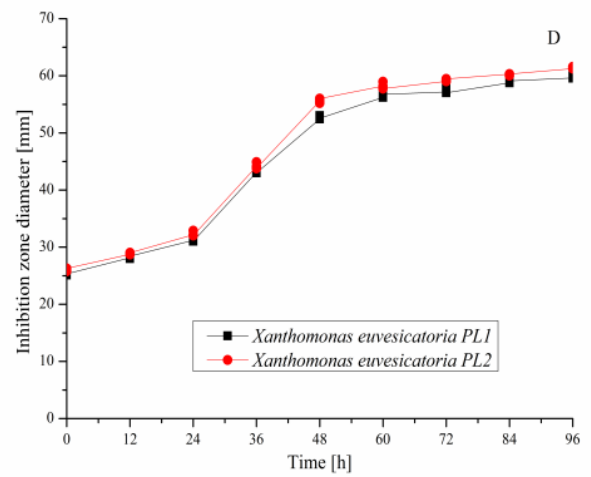

(d)

Figure 5. Course of B. velezensis IP22 cultivation in the laboratory-scale bioreactor in terms of: (a) $\mathrm{pH}$ value, (b) residual nutrients' content, (c) biomass content, (d) antimicrobial activity against $X$. euvesicatoria isolates.

When it comes to residual concentration of the main nutrients (glycerol, total nitrogen, and total phosphorus) during the cultivation, it can be noticed that in the first $24 \mathrm{~h}$ of cultivation, slight decrease of nutrients' content had occurred (Figure $5 b$ ) due to adaptation of B. velezensis IP22 from metabolizing sugars from nutrient broth used for inoculum preparation to glycerol as the main carbon source of cultivation medium in the bioreactor [38]. Sharper decrease in the nutrients' content could be observed between the 24th and the 60th hour (Figure 5b) due to the exponential growth phase, which could also be observed in Figure $5 c$, where biomass content has drastically increased in the same period of the cultivation. After $60 \mathrm{~h}$ of cultivation, only slight change in nutrients' content, as well as in biomass content, was noticed, corresponding to the stationary growth phase, where the number of newly formed bacterial cells is approximate to the number of dying bacterial cells, which is also confirmed by the stagnation of optical density of the cultivation broth (Figure 5c). Monitoring of 
inhibition zone diameters (Figure 5d) against X. euvesicatoria has suggested that the trend of their change has approximately followed the trend of biomass content change, as well as the trend of nutrients' consumption. The results of antimicrobial activity testing using the cultivation broth sample from the end of the validation experiment (96th hour) against X. euvesicatoria PL1 and PL2 are given in Figure 6.

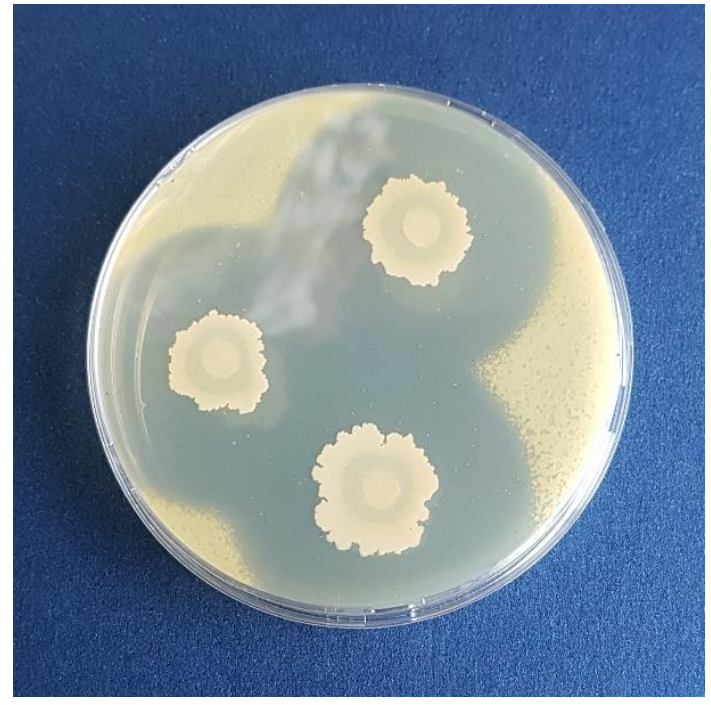

(a)

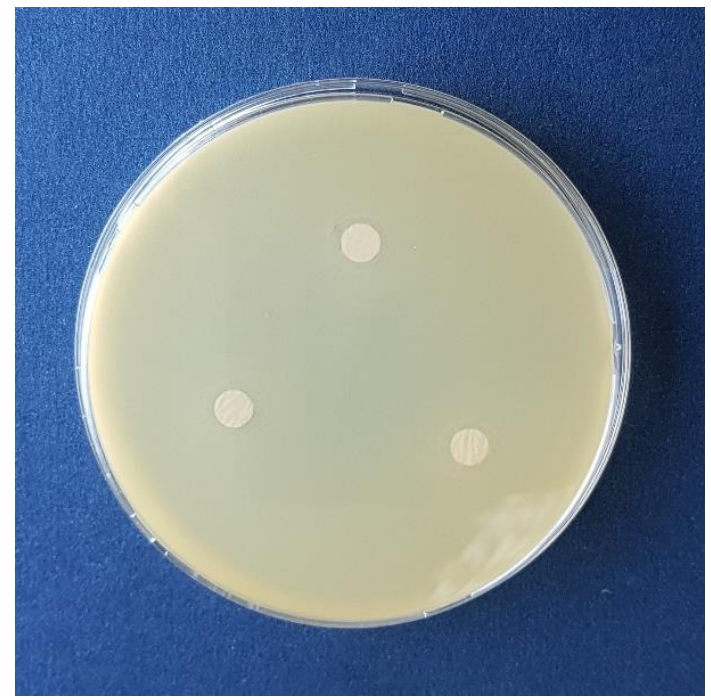

(b)

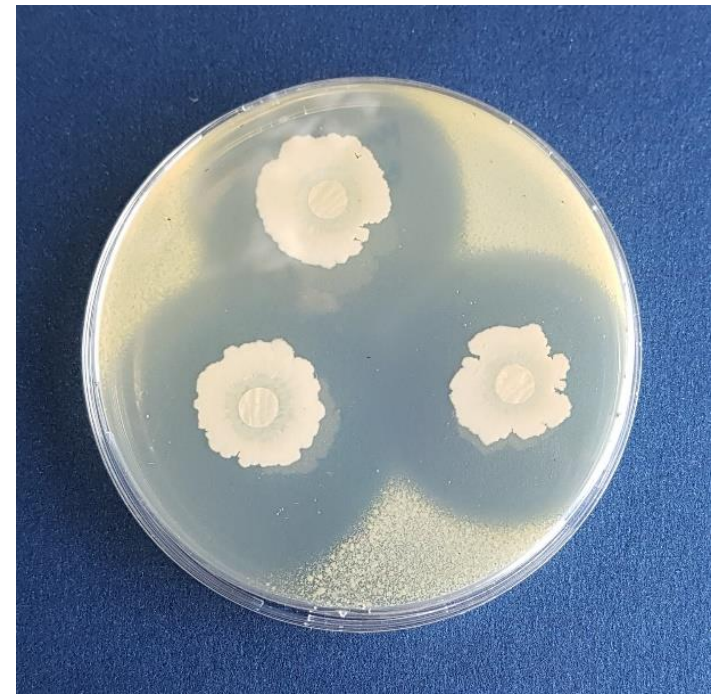

(c)

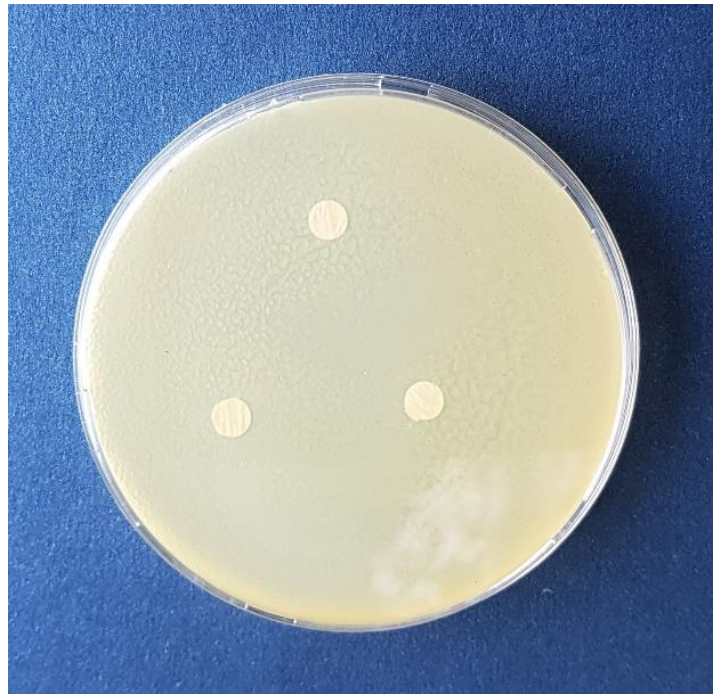

(d)

Figure 6. Inhibition zone diameters obtained as a result of in vitro antimicrobial activity testing against X. euvesicatoria: (a) cultivation broth sample from the end of the validation experiment against $X$. euvesicatoria PL1, (b) negative control-X. euvesicatoria PL1, (c) cultivation broth sample from the end of the validation experiment against X. euvesicatoria PL2, (d) negative control-X. euvesicatoria PL2. 
3.5. HPLC-MS Analysis of Antimicrobial Compounds Produced by B. velezensis IP22

In order to determine the ability of the producing microorganism B. velezensis IP22 to produce antimicrobial lipopeptides, HPLC-MS analysis was performed using the supernatant obtained after centrifugation of the cultivation broth sample from the end of the validation experiment. The obtained SIM chromatograms are given in Figures 7 and 8 , while the obtained $m / z$ values of the produced antimicrobial compounds were compared to literature data. The obtained results are summarized in Table 4.

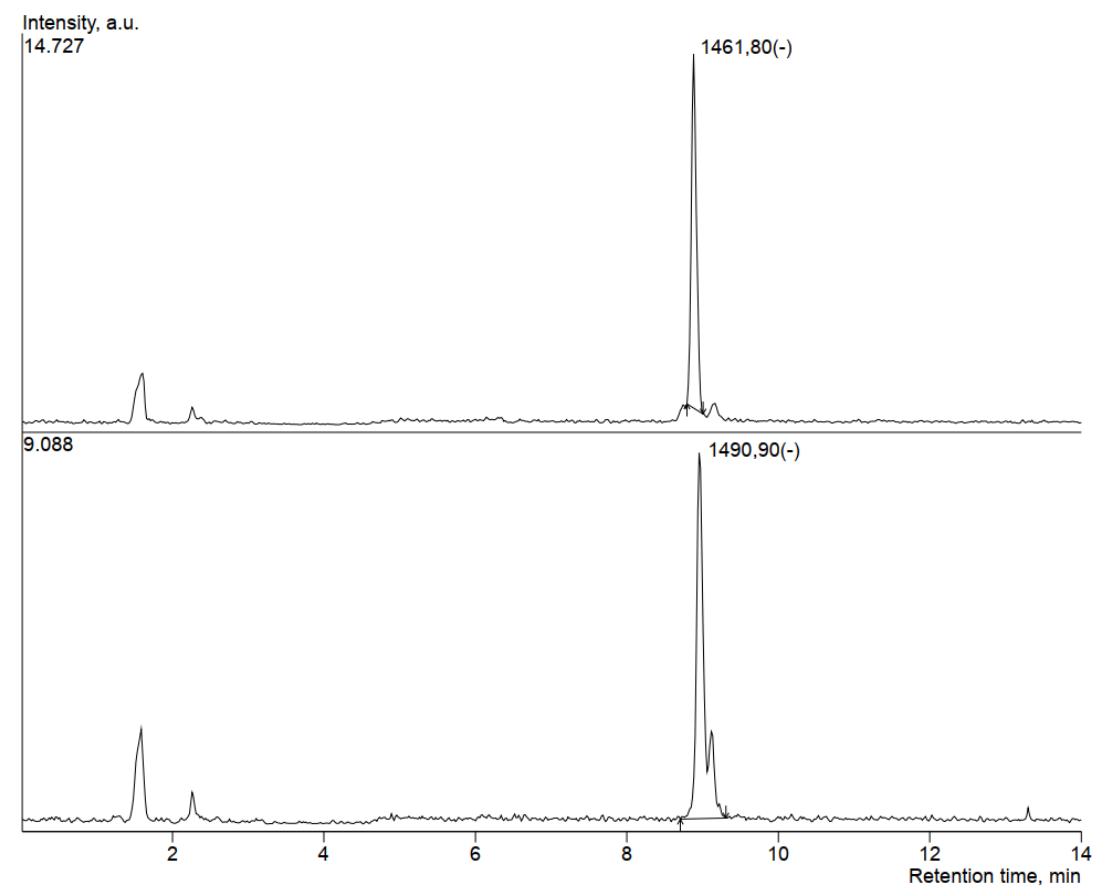

Figure 7. SIM (selected ion monitoring) chromatograms of the antimicrobial compounds from the fengycin family putatively identified in the supernatant of B. velezensis IP22 cultivation broth.

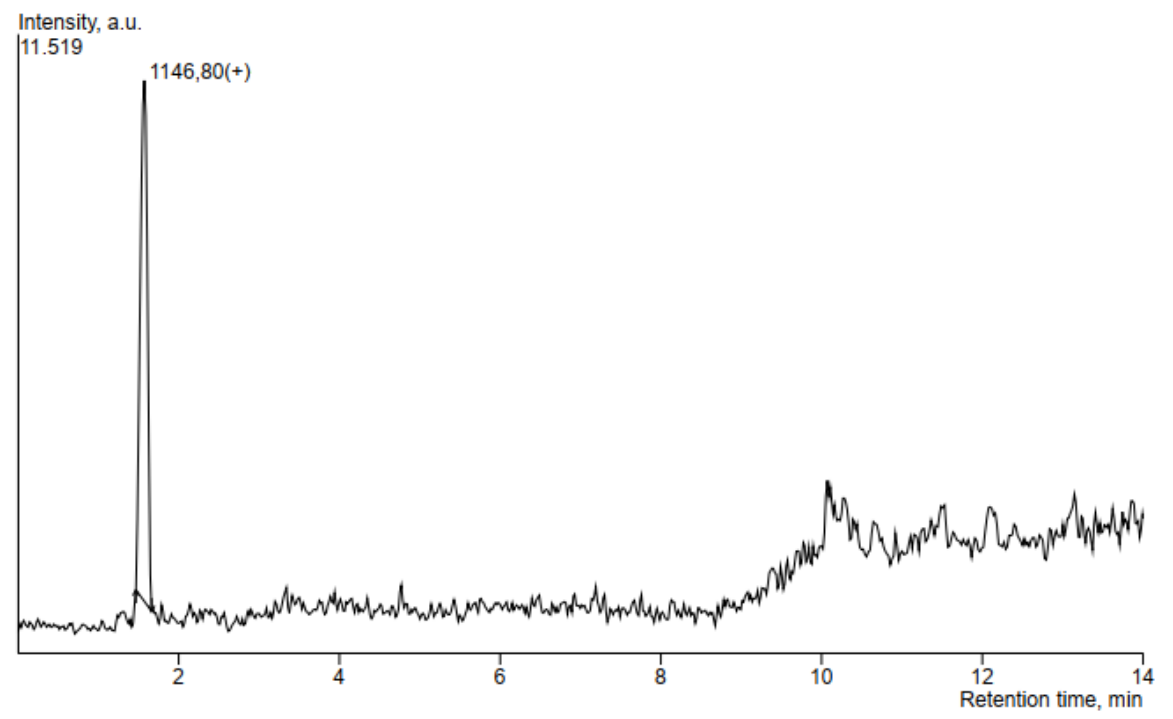

Figure 8. SIM chromatogram of the antimicrobial compound from the locillomycin family putatively identified in the supernatant of B. velezensis IP22 cultivation broth. 
Table 4. Antimicrobial compounds putatively identified by the HPLC-MS (high pressure liquid chromatography-mass spectrometry) in the supernatant of $B$. velezensis IP22 cultivation broth.

\begin{tabular}{cccc}
\hline Putatively Identified Compound & Retention Time (min) & Peak Area & $m / z$ \\
\hline Fengycin & 8.883 & 62897 & 1461.8 \\
Fengycin & 1.603 & 12026 & 1489.7 \\
Fengycin & 8.96 & 60938 & 1490.9 \\
Locillomycin & 1.574 & 44514 & 1146.8 \\
\hline
\end{tabular}

In this study, compounds identified at $m / z$ values of $1461.8,1489.7$, and 1490.9 suggest the presence of fengycins in the supernatant of cultivation broth obtained by cultivation of $B$. velezensis IP22 (Figure 7) [39-44].

The detected mass in 1146.8 (Figure 8) pointed to the presence of locillomycin, a relatively new lipopeptide family that has been synthesized by the bacteria of the genus Bacillus [45].

\subsection{In Planta Experiments with Pepper Plants}

In planta testing of biocontrol activity in pepper plants was performed using the cultivation broth of B. velezensis IP22 obtained in the validation experiment in the laboratory-scale bioreactor. Bacterial spot causal agents used for in planta testing were two X. euvesicatoria strains (PL1 and PL2) isolated from leaves of the diseased pepper plants. The resulting symptoms of pepper bacterial spot in the tested plants were recorded five weeks after a preventive treatment with B. velezensis IP22 cultivation broth and inoculation with pathogens. The results of in planta testing are summarized in Table 5 and presented in Figure 9.

In plants treated with $B$. velezensis IP22 cultivation broth, the symptoms of bacterial spot could be observed only at the spot where artificial inoculation with phytopathogenic X. euvesicatoria strains was performed (Figure 9), while the spreading of the disease symptoms outside of the inoculation spot on infected leaves was not noticed, which could be concluded from a significantly smaller value of leaf area covered by the necrosis caused by pathogen spreading (Table 5). In addition, further infection of other uninoculated leaves in the plants inoculated with phytopathogenic strains similarly was not observed (Figure 9). On the other hand, in the control plants that were not treated by B. velezensis IP22 cultivation broth, it could be observed that leaf necrosis had spread outside the inoculation area, covering 4-9 folds larger leaf area compared to the treated plants (Table 5). In addition, in untreated and inoculated control plants, symptoms of bacterial spot were also noticed on the leaves which were not directly inoculated, suggesting the disease spreading on $68-81 \%$ of total number of leaves, depending on the phytopathogenic isolate (Table 5). Furthermore, from the presented results, it could be also concluded that phytopathogenic isolate X. euvesicatoria PL 2 has caused more severe bacterial spot symptoms in pepper plants, which has also been confirmed by different levels of statistical significance when it comes to disease symptoms caused by PL1 and PL2 strains, but at the same time, its suppression by B. velezensis IP22 cultivation broth has been slightly more successful (Table 5, Figure 9).

Table 5. The results of in planta antimicrobial activity assaying of the produced biocontrol agents based on $B$. velezensis IP22 against X. euvesicatoria strains, the causal agents of pepper bacterial spot.

\begin{tabular}{ccc}
\hline Plant & Infected Leaves (\%) & Leaf Necrosis (\%) \\
\hline 1 & $0.00 \pm 0.00^{\mathrm{a}}$ & $0.00 \pm 0.00^{\mathrm{a}}$ \\
$2 \mathrm{~A}$ & $68.33 \pm 1.67^{\mathrm{b}}$ & $31.97 \pm 0.14^{\mathrm{b}}$ \\
2B & $80.95 \pm 2.38^{\mathrm{c}}$ & $44.43 \pm 3.34^{\mathrm{c}}$ \\
3A & $14.84 \pm 0.55^{\mathrm{d}}$ & $7.51 \pm 1.76^{\mathrm{d}}$ \\
3B & $14.84 \pm 0.55^{\mathrm{d}}$ & $5.09 \pm 0.09^{\mathrm{e}}$ \\
\hline
\end{tabular}

A-X. euvesicatoria PL1, B-X. euvesicatoria PL2. 1-negative control, 2-positive control, 3-treated plants. Superscript letters $\left({ }^{a-e}\right)$ represent different levels of statistical significance. Values in the same column marked with the same superscript letter are at the same level of significance with confidence level of 95\% (Duncan's test). 

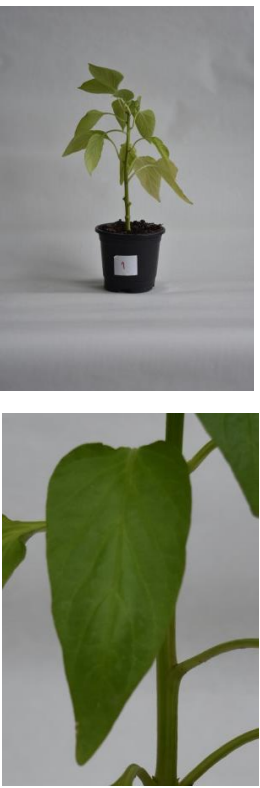

(a)
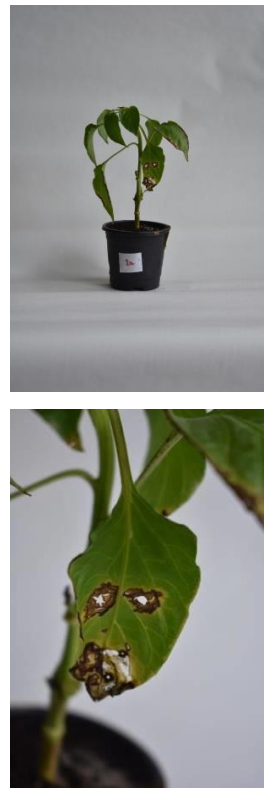

(b)
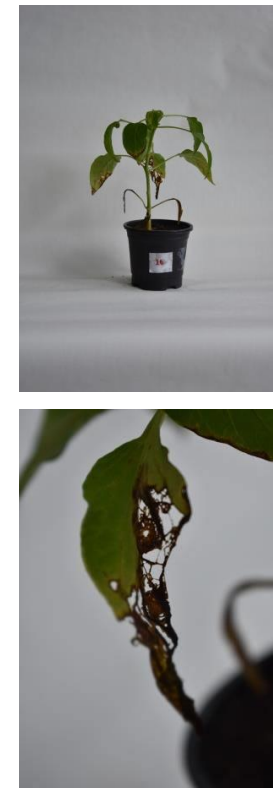

(c)
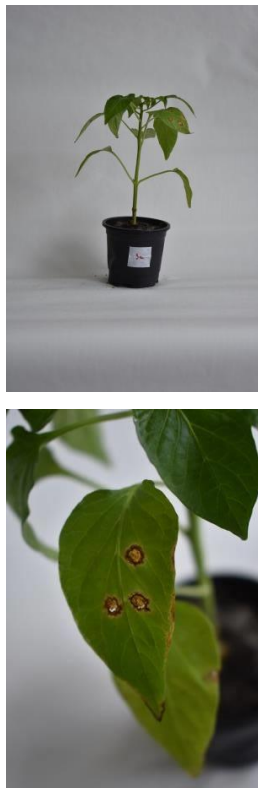

(d)
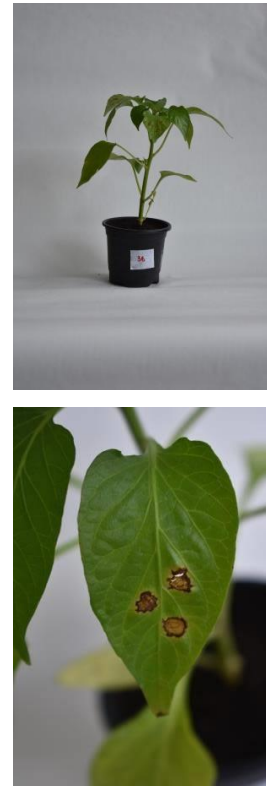

(e)

Figure 9. The results of in planta testing of the produced biocontrol agents based on B. velezensis IP22 against X. euvesicatoria: (a) uninoculated and untreated control (negative control-plant 1 ), (b) untreated control inoculated with X. euvesicatoria PL 1 (positive control-plant 2A), (c) untreated control inoculated with X. euvesicatoria PL 2 (positive control-plant 2B), (d) plant treated with B. velezensis cultivation broth and inoculated with X. euvesicatoria PL 1 (plant 3A), (e) plant treated with B. velezensis cultivation broth and inoculated with X. euvesicatoria PL 2 (plant 3B).

\section{Discussion}

After molecular identification of the producing microorganism as Bacillus velezensis IP22 using $16 \mathrm{~S}$ rDNA sequencing, the next step in development of the bioprocess aimed at production of the biocontrol agent effective against $X$. euvesicatoria phytopathogens was to formulate a medium suitable for cultivation of the producing microorganism and production of a highly-effective biocontrol agent. Since it was previously established that B. velezensis IP22 successfully utilizes glycerol as the carbon source for production of biocontrol agents and that combination of glycerol as the carbon source and yeast extract as the organic nitrogen source is optimal for maximization of its antimicrobial potential [46], the next step was modeling and optimization of the cultivation medium composition based on these nutrients' content. Besides glycerol and yeast extract, concentrations of $\left(\mathrm{NH}_{4}\right)_{2} \mathrm{SO}_{4}$ as the inorganic nitrogen source and $\mathrm{K}_{2} \mathrm{HPO}_{4}$ as the phosphorus source were also used as independent variables. The outputs, i.e., the monitored dependent variables were: inhibition zone diameters obtained by testing of antimicrobial activity of B. velezensis IP22 cultivation broth samples against X. euvesicatoria isolates PL1 and PL2, as well as residual content of glycerol, total nitrogen, and total phosphorus in the cultivation broth at the end of B. velezensis IP22 cultivation. Application of statistical modeling, using the second degree polynomial models, has showed satisfying results since the obtained models were statistically significant at the level of 99\%. RSM (response surface methodology) has also revealed some useful insights into interactions of nutrients used in the cultivation medium and their effects on inhibition zone diameter, as the main dependent variable corresponding to $B$. velezensis IP22 antimicrobial activity against X. euvesicatoria. The RSM results have indicated high demand of the producing microorganism for nitrogen and phosphorus sources, which are mostly utilized for biomass growth and multiplication due to synthesis of cell components, such as phospholipids, proteins, and DNA [47], in order to achieve maximal antimicrobial activity against X. euvesicatoria, while the initial content of glycerol as the carbon source could be kept near minimal value of the examined range (10-60 g/L). 
A further step in bioprocess development was optimization of the cultivation medium composition in terms of concentration of the main nutrients (carbon source, organic and inorganic nitrogen source, and phosphorus source), in order to produce a sufficiently effective biocontrol agent with maximized antimicrobial activity to be used against X. euvesicatoria. In this study, optimization was carried out using the desirability function method. The first optimization set had only one goal: to maximize the inhibition zone diameter of B. velezensis IP22 cultivation broth samples against X. euvesicatoria, i.e., to maximize antimicrobial activity of the producing microorganism. The optimized values of nutrients' content, as well as the predicted value of inhibition zone diameter were in accordance with previously discussed results obtained using RSM: minimal concentration of glycerol and almost maximal concentration of yeast extract, $\left(\mathrm{NH}_{4}\right)_{2} \mathrm{SO}_{4}$, and $\mathrm{K}_{2} \mathrm{HPO}_{4}$ from the examined range are required to obtain maximal inhibition zone diameter. However, the predicted values of residual nutrients' content using the optimized cultivation medium composition were still very high, indicating possible presence of these nutrients in bioprocess effluents, which could represent a major problem for safe and sustainable disposal or treatment of bioprocess wastestreams [48]. Therefore, the second set of optimization of cultivation medium composition had the following goal defined: minimization of residual nutrients' content, along with maximization of B. velezensis IP22 antimicrobial activity. The results of the second optimization set have shown a possibility to decrease initial nutrients' content in the cultivation medium for $16.74 \%, 30.30 \%$, and even $86.81 \%$ in the case of glycerol, yeast extract, and $\mathrm{K}_{2} \mathrm{HPO}_{4}$, respectively. On the other hand, the $\left(\mathrm{NH}_{4}\right)_{2} \mathrm{SO}_{4}$ content should be increased for $11.52 \%$, compared to the results of the first optimization set, probably due to decrease of nitrogen content arisen from a reduction of initial yeast extract concentration. These results indicate the possibility to significantly reduce the cost of the cultivation medium, contributing to the reduction of the total bioprocess cost. When it comes to the predicted values of residual nutrients' content, it can be seen that they were reduced compared to the first optimization set: glycerol by $31.22 \%$, total nitrogen content by $42.5 \%$, and total phosphorus content by $95.32 \%$. The most significant achievement in this particular case is the reduction of residual phosphorus content, considering that phosphorus, originating from wastestreams disposed in the natural aquatic ecosystems, is the main nutrient responsible for eutrophication [49]. Nevertheless, it can also be noticed that the predicted value of the inhibition zone diameter, and therefore, also the desirability function value, were reduced. The reduction of $9.47 \%$ in the inhibition zone diameter value, however, should not present a major loss of antimicrobial activity compared to the savings and benefits that could be achieved using the cultivation medium of the optimized composition, where further techno-economic analysis of the bioprocess should be employed to address the overall bioprocess cost-effectiveness.

In order to validate the obtained models for the selected dependent variables (inhibition zone diameter and residual glycerol, total nitrogen, and total phosphorus content) and the optimized values of nutrients' content in the cultivation medium, as well as concurrence of the predicted values of dependent variables with their actual values, validation experiments were carried out by cultivating B. velezensis IP22 in a laboratory-scale bioreactor with working volume of 2 L. Monitoring of the B. velezensis IP22 cultivation course has revealed a typical bacterial growth curve, with the adaptation phase in the first $24 \mathrm{~h}$, followed by the exponential phase (24th-60th hour) and the stationary phase observed after $60 \mathrm{~h}$ of cultivation. Consumption of nutrients by B. velezensis IP22 during the cultivation has followed biomass growth. However, it was interesting to notice that the trend of antimicrobial activity of cultivation broth samples against X. euvesicatoria has also followed the trend of biomass growth, where only slight changes in inhibition zone diameters could be observed during the stationary growth phase. These results indicate that cultivation duration could be reduced from 96 to $60 \mathrm{~h}$, in order to reduce the bioprocess cost due to energy and labor savings, as well as the possibility to exploit bioprocess equipment more efficiently by increasing the number of production cycles per year. On the other hand, analysis of residual content of nutrients and inhibition zone diameters of cultivation broth samples against $X$. euvesicatoria at the end of the cultivation has revealed a significant match between observed values $(1.36 \mathrm{~g} / \mathrm{L}$ for glycerol content, $0.90 \mathrm{~g} / \mathrm{L}$ for total nitrogen content, $0.15 \mathrm{~g} / \mathrm{L}$ 
for total phosphorus content, and $60.55 \mathrm{~mm}$ for inhibition zone diameter) and the values predicted during the modeling of cultivation medium composition (Table 3). This matching, i.e., confirmation of validity of the obtained models for the inhibition zone diameter and residual content of glycerol, total nitrogen, and total phosphorus, indicates the applicability of the obtained models, as well as the optimized cultivation medium, for production of biocontrol agents effective against the causal agent of pepper bacterial spot X. euvesicatoria even at a larger production scale.

Since $B$. velezensis expresses several mechanisms of antimicrobial activity, such as competition for growth space and nutrients [18], production of volatile compounds [27], antimicrobial lipopeptides [17], and enzymes [18], one of the aims of this study was to investigate antimicrobial compounds produced by the $B$. velezensis IP22 strain isolated from fresh cheese, with proven in vitro antimicrobial activity against the causal agent of pepper bacterial spot X. euvesicatoria. With that purpose, samples of cultivation broth at the end of the cultivation in a laboratory-scale bioreactor were centrifuged, and supernatants were further analyzed using the HPLC-MS method. HPLC-MS analysis revealed presence of three lipopeptides putatively identified as members of the fengycin family and one lipopeptide putatively identified as a member of the locillomycin family, by comparing the obtained $\mathrm{m} / \mathrm{z}$ values with literature data, as discussed in the following sentences. The fengycin family consists of lipopeptides with dominant antifungal activity, while the most probable mechanism of fungicidal action is disruption of cell membrane structure [50]. Fengycins with saturated fatty acid chains were detected in the $\mathrm{m} / \mathrm{z}$ range of 1435.8-1505.8, while fengycins with unsaturated fatty acid chain with one double bond were detected in the $m / z$ range of 1433.8-1489.8 [39]. Toral et al. [40] identified fengycin B with $16 \mathrm{C}$-atoms in the fatty acid chain at $m / z 1491.8[\mathrm{M}+\mathrm{H}]^{+}$. Fengycin with $16 \mathrm{C}$-atoms in the fatty acid chain has also been identified at $m / z 1463.8[\mathrm{M}+\mathrm{H}]^{+}$[41]. Fengycins, which contain alanine at the sixth position in the peptide chain, have been identified at $m / z$ values of $1471.9[\mathrm{M}+\mathrm{Na}]^{+}, 1485.9[\mathrm{M}+\mathrm{Na}]^{+}, 1499.9[\mathrm{M}+\mathrm{Na}]^{+}$, for the compounds with 15, 16 and 17 C-atoms in the fatty acid chain, respectively [42]. According to de Fillippi et al. [43], fengycins A have been identified in $m / z$ range of $1464-1506[\mathrm{M}+\mathrm{H}]^{+}$, while fengycins B have been detected in the $m / z$ range of $1462-1490[\mathrm{M}+\mathrm{H}]^{+}$. Adeniji et al. [44] identified fengycins in the $m / z$ range of 1449.9-1515.9. Recent study has confirmed antibacterial effect of fengycins against Xanthomonas axonopodis pv. vesicatoria by causing alterations on the cell surface and loss of intracellular content [51]. On the other hand, lipopeptide putatively identified as locillomycin was detected at $\mathrm{m} / \mathrm{z}$ value of 1146.8, representing a relatively novel family of lipopeptides which exhibit antibacterial and antiviral activity, but also limited antifungal activity [45,52].

In order to assess suitability of the B. velezensis IP22 cultivation broth produced in the previously explained way to be used as a biocontrol agent against pepper bacterial spot, in planta tests with pepper plants were performed. Plants treated by the biocontrol agent and artificially inoculated using X. euvesicatoria strains PL1 and PL2, as well as positive and negative controls, were cultivated and monitored for symptoms of bacterial spot for five weeks. The preventive treatment of pepper plants with $B$. velezensis IP22 cultivation broth has significantly contributed to the suppression of phytopathogenic $X$. euvesicatoria strains, as well as to reduction of disease symptoms spreading. Differences in plant coloration between treated and untreated plants can be explained by promoting effects that $B$. velezensis has on plants as a part of its modes of action involved in antimicrobial activity, which is in agreement with recent studies on this agent [53-56] and which is yet to be investigated in our future studies. The results of in planta assaying suggest the high potential of biocontrol agents based on B. velezensis IP22 produced in the previously described way under the optimized production conditions at a laboratory scale in suppression of pepper bacterial spot caused by X. euvesicatoria strains. Hence, the validity of the proposed bioprocess solution for production of pepper bacterial spot biocontrol agent was confirmed, opening a new chapter of possibilities for scale-up of this bioprocess to a pilot and an industrial scale. 


\section{Conclusions}

Results presented in this study indicate significant potential of B. velezensis IP22 to be used as a biocontrol agent for bacterial spot of pepper. Composition of cultivation medium for biotechnological production of biocontrol agents based on B. velezensis IP22 was optimized in order to maximize biocontrol activity against the tested X. euvesicatoria strains, but also to minimize residual content of nutrients in the cultivation broth in order to reduce costs of biotechnological production and make step further towards a sustainable production process. Validity of the optimized medium composition was confirmed in the experiments performed in the laboratory-scale bioreactor. The validation experiment has also given a useful insight into the possibility to reduce bioprocess duration from 96 to $60 \mathrm{~h}$, which would contribute to reduction of the overall bioprocess cost. In planta experiments have confirmed the results of in vitro assays and significant potential of B. velezensis IP22 cultivation broth to be used in suppression of pepper bacterial spot. In addition, there is a wide spectrum of possible ways to improve the existing liquid formulation in order to increase its efficiency at the application site and to maintain viability of $B$. velezensis IP22 cells in a longer time period aimed at prolongation of the expiry date of the final product in which the guaranteed activity against the target phytopathogens should be delivered. Furthermore, the most pronounced mechanism of antimicrobial activity of the produced biocontrol agent is to be identified. Confirmation of the ability of B. velezensis IP22 to synthesize antimicrobial lipopeptides has opened a new chapter of possibilities to optimize cultivation medium composition in such order to achieve maximal concentration of the desired antimicrobial compounds in the resulting cultivation broth which will be lately applied as a biocontrol agent. Further research will be aimed at investigation of biocontrol activity of the produced agents based on B. velezensis IP22 in real application conditions, i.e., in the field, as well as at defining the optimal application method, dosage, and timing.

Supplementary Materials: Supplementary materials can be found at http://www.mdpi.com/2076-2607/8/10/1463/ s1. Table S1. PCR conditions for identification of pathogens using the species-specific primers for X. euvesicatoria. Table S2. Box-Behnken experimental plan for optimization of medium composition for Bacillus IP22 cultivation.

Author Contributions: Conceptualization, J.G., I.P. and M.G.; methodology, J.G., I.P., M.G., V.V., M.M. and S.G.; software, J.G. and I.P.; validation, I.P. and V.V.; formal analysis, I.P., V.V., M.M. and S.G.; investigation, I.P. and V.V.; resources, J.G., M.G., M.M. and M.F.; data curation, J.G. and I.P.; writing-original draft preparation, I.P.; writing-review and editing, J.G., S.G. and M.G.; visualization, J.G., I.P., M.G., M.M. and S.G.; supervision, J.G. and M.F.; project administration, J.G. and M.F.; funding acquisition, J.G. and M.F. All authors have read and agreed to the published version of the manuscript.

Funding: This research was funded by the Ministry of Education, Science and Technological Development of the Republic of Serbia, grant number 451-03-68/2020-14/200134, and by the Autonomous Province of Vojvodina-Provincial Secretariat for Higher Education and Scientific Research within the framework of the Short-term project of a special interest for sustainable development in the AP Vojvodina entitled "Implementation of circular economy principles in technology of production of biocontrol agents", grant number 142-451-3243/2020-03.

Acknowledgments: Identification of Xanthomonas strains was conducted in the Laboratory for seed testing at the Institute of Field and Vegetable Crops (Novi Sad, Serbia) with kind assistance of Maja Ignjatov. The HPLC-MS analysis of antimicrobial lipopeptides was performed in the framework of the COST Action CA15110 (grant number 43178 awarded to Vanja Vlajkov).

Conflicts of Interest: The authors declare no conflict of interest. The funders had no role in the design of the study; in the collection, analyses, or interpretation of data; in the writing of the manuscript, or in the decision to publish the results.

\section{References}

1. Potnis, N.; Timilsina, S.; Strayer, A.; Shantharaj, D.; Barak, J.D.; Paret, M.L.; Vallad, G.E.; Jones, J.B. Bacterial spot of tomato and pepper: Diverse Xanthomonas species with a wide variety of virulence factors posing a worldwide challenge. Mol. Plant Pathol. 2015, 16, 907-920. [CrossRef] [PubMed]

2. EPPO. PM 7/110 (1) Xanthomonas spp. (Xanthomonas euvesicatoria, Xanthomonas gardneri, Xanthomonas perforans, Xanthomonas vesicatoria) causing bacterial spot of tomato and sweet pepper. Oepp/Eppo Bull. 2013, 43, 7-20. [CrossRef] 
3. Bashan, Y.; Diab, S.; Okon, Y. Survival of Xanthomonas campestris pv. vesicatoria in pepper seeds and roots, in symptomless and dry leaves in non-host plants and in the soil. Plant Soil. 1982, 68, 161-170. [CrossRef]

4. Diab, S.; Bashan, Y.; Okon, Y. Studies on infection with Xanthomonas campestris pv. vesicatoria, causal agent of bacterial scab of pepper in Israel. Phytoparasitica 1982, 10, 183-191. [CrossRef]

5. Diab, S.; Bashan, Y.; Okon, Y.; Henis, Y. Effects of relative humidity on bacterial scab caused by Xanthomonas campestris pv. vesicatoria on pepper. Phytopathology 1982, 72, 1257-1260. [CrossRef]

6. Zhang, Y.; Callaway, E.; Jones, J.B.; Wilson, M. Visualisation of hrp gene expression in Xanthomonas euvesicatoria in the tomato phyllosphere. Eur. J. Plant Pathol. 2009, 124, 379-390. [CrossRef]

7. Hassan, E.O.; Zyton, M.A. Management of bacterial spot of pepper caused by Xanthomonas campestris pv. vesicatoria. Am. J. Biosci. Bioeng. 2017, 5, 41-49. [CrossRef]

8. Ignjatov, M. Diversity of Xanthomonas spp. Population-Pepper Pathogens in Serbia. PhD Thesis, Faculty of Agriculture, University of Belgrade, Belgrade, Serbia, 2013.

9. Aysan, Y.; Sahin, F. Occurrence of bacterial spot disease, caused by Xanthomonas axonopodis pv. vesicatoria on pepper in the eastern Mediterranean region of Turkey. Plant Pathol. 2003, 52, 781. [CrossRef]

10. Balaž, J.; Delibašić, T. Devising methods for isolation of Xanthomonas campestris pv. vesicatoria from pepper seed. Pestic. Phytomed. 2005, 20, 51-60.

11. Griffin, K.; Gambley, C.; Brown, P.; Li, Y. Copper-tolerance in Pseudomonas syringae pv. tomato and Xanthomonas spp. and the control of diseases associated with these pathogens in tomato and pepper. A systematic literature review. Crop. Prot. 2017, 96, 144-150. [CrossRef]

12. Vallad, G.E.; Pernezny, K.L.; Balogh, B.; Wen, A.; Figueiredo, J.F.L.; Jones, J.B.; Momol, T.; Muchovej, R.M.; Havranek, N.; Abdallah, N.; et al. Comparison of kasugamycin to traditional bactericides for the management of bacterial spot on tomato. HortScience 2010, 45, 1834-1840. [CrossRef]

13. Buonaurio, R.; Scarponi, L.; Ferrara, M.; Sidoti, P.; Bertona, A. Induction of systemic acquired resistance in pepper plants by acibenzolar-S-methyl against bacterial spot disease. Eur. J. Plant Pathol. 2002, 108, 41-49. [CrossRef]

14. Gašić, K.; Kuzmanović, N.; Ivanović, M.; Prokić, A.; Šević, M.; Obradović, A. Complete genome of the Xanthomonas euvesicatoria specific bacteriophage $\mathrm{K} \Phi 1$, its survival and potential in control of pepper bacterial spot. Front. Microbiol. 2018, 9, 2021. [CrossRef] [PubMed]

15. Sević, M.; Gašić, K.; Đorđevic, M.; Ignjatov, M.; Mijatović, M.; Zečević, B.; Obradović, A. Efficacy of biocontrol agents and bactericides in control of pepper bacterial spot. Acta Hortic. 2016, 1142, 147-150. [CrossRef]

16. Gotor-Vila, A.; Usall, J.; Torres, R.; Abadias, M.; Teixidó, N. Formulation of the biocontrol agent Bacillus amyloliquefaciens CPA-8 using different approaches: Liquid, freeze-drying and fluid-bed spray-drying. BioControl 2017, 62, 545-555. [CrossRef]

17. Zhao, P.; Xue, Y.; Gao, W.; Li, J.; Zu, X.; Fu, D.; Bai, X.; Zuo, Y.; Hu, Z.; Zhang, F. Bacillaceae-derived peptide antibiotics since 2000. Peptides 2018, 101, 10-16. [CrossRef]

18. Shafi, J.; Tian, H.; Ji, M. Bacillus species as versatile weapons for plant pathogens: A review. Biotechnol. Biotechnol. Equip. 2017, 31, 446-459. [CrossRef]

19. Gomaa, E.Z. Antimicrobial activity of a biosurfactant produced by Bacillus licheniformis strain M104 grown on whey. Braz. Arch. Biol. Technol. 2013, 56, 259-268. [CrossRef]

20. Abiala, M.; Odebode, A.; Hsu, S.; Blackwood, C. Phytobeneficial properties of bacteria isolated from the rhizosphere of maize in southwestern Nigerian soils. Appl. Environ. Microbiol. 2015, 81, 4736-4743. [CrossRef]

21. Dunlap, C.A.; Kim, S.J.; Kwon, S.W.; Rooney, A.P. Bacillus velezensis is not a later heterotypic synonym of Bacillus amyloliquefaciens; Bacillus methylotrophicus, Bacillus amyloliquefaciens subsp. plantarum and 'Bacillus oryzicola' are later heterotypic synonyms of Bacillus velezensis based on phylogenomics. Int. J. Syst. Evol. Microbiol. 2016, 66, 1212-1217. [CrossRef]

22. Wu, G.; Liu, Y.; Xu, Y.; Zhang, G.; Shen, Q.; Zhang, R. Exploring elicitors of the beneficial rhizobacterium Bacillus amyloliquefaciens SQR9 to induce plant systemic resistance and their interactions with plant signaling pathways. Mol. Plant-Microbe Interact. 2018, 5, 560-567. [CrossRef] [PubMed]

23. Chen, L.; Shi, H.; Heng, J.; Wang, D.; Bian, K. Antimicrobial, plant growth-promoting and genomic properties of the peanut endophyte Bacillus velezensis LDO2. Microbiol. Res. 2019, 218, 41-48. [CrossRef] [PubMed]

24. Jiang, C.-H.; Liao, M.-J.; Wang, H.-K.; Zheng, M.-Z.; Xu, J.-J.; Guo, J.-H. Bacillus velezensis, a potential and efficient biocontrol agent in control of pepper gray mold caused by Botrytis cinerea. Biol. Control 2018, 126, 147-157. [CrossRef] 
25. Guo, R.J.; Wang, J.Q.; Li, S.D.; Jing, Y.L.; Gao, Y.H.; Sun, R.L. A Bacillus velezensis Strain and Its Application with Mutifunctions in Suppressing Disease Occurrence, Promoting Plant Growth and Drought Resistance. Patent application number CH20181001.8 2018.

26. Wang, J.; Guo, R.; Wang, W.; Ma, G.; Li, S. Insight into the surfactin production of Bacillus velezensis B006 through metabolomics analysis. J. Ind. Microbiol. Biotechnol. 2018, 45, 1033-1044. [CrossRef] [PubMed]

27. Gao, Z.; Zhang, B.; Liu, H.; Han, J.; Zhang, Y. Identification of endophytic Bacillus velezensis ZSY-1 strain and antifungal activity of its volatile compounds against Alternaria solani and Botrytis cinerea. Biol. Control 2017, 105, 27-39. [CrossRef]

28. Meng, Q.; Jiang, H.; Hao, J.J. Effects of Bacillus velezensis strain BAC03 in promoting plant growth. Biol. Control 2016, 98, 18-26. [CrossRef]

29. Chowdhury, S.P.; Hartmann, A.; Gao, X.; Borriss, R. Biocontrol mechanism by root-associated Bacillus amyloliquefaciens FZB42-A review. Front. Microbiol. 2015, 6, 780. [CrossRef]

30. Moretti, C.; Amatulli, M.T.; Buonaurio, R. PCR-based assay for the detection of Xanthomonas euvesicatoria causing pepper and tomato bacterial spot. Appl. Microbiol. 2009, 49, 466-471. [CrossRef]

31. Nikodinovic, J.; Barrow, K.D.; Chuck, J.A. High yield preparation of genomic DNA from Streptomyces. BioTechniques 2003, 35, 932-934. [CrossRef]

32. Reysenbach, A.L.; Wickham, G.S.; Pace, N.R. Phylogenetic analysis of the hyperthermophilic pink filament community in Octopus Spring, Yellowstone National Park. Appl. Environ. Microbiol. 1994, 60, 2113-2119. [CrossRef]

33. Kumar, S.; Stecher, G.; Tamura, K. MEGA7: Molecular Evolutionary Genetics Analysis version 7.0 for bigger datasets. Mol. Biol. Evol. 2016, 33, 1870-1874. [CrossRef] [PubMed]

34. Herlich, K. Official Methods of Analysis of the Association of Official Analytical Chemists, 15th ed.; Association of Official Analytical Chemists: Arlington, VA, USA, 1990.

35. Gales, M.E.J.; Julian, E.C.; Kroner, R.C. Method for quantitative determination of total phosphorus in water. J. Am. Water Work. Ass. 1966, 58, 1363-1368. [CrossRef]

36. Smyth, T.J.; Perfumo, A.; McClean, S.; Marchant, R.; Banat, I.M. Isolation and analysis of lipopeptides and high molecular weight biosurfactants. In Handbook of Hydrocarbon and Lipid Microbiology: Biochemical Methods; McGenity, T.J., Timmis, K.N., Nogales, B., Eds.; Springer: Heidelberg, Germany, 2016; pp. 3687-3704.

37. Tamura, K.; Nei, M. Estimation of the number of nucleotide substitutions in the control region of mitochondrial DNA in humans and chimpanzees. Mol. Biol. Evol. 1993, 10, 512-526. [CrossRef] [PubMed]

38. Pajčin, I.; Rončević, Z.; Dodić, J.; Dodić, S.; Grahovac, M.; Jokić, A.; Grahovac, J. Effect of different inoculum preparation conditions on the biomass growth and antimicrobial activity of Bacillus sp. J. Process. Energy Agric. 2019, 23, 96-100. [CrossRef]

39. Mejri, S.; Siah, A.; Coutte, F.; Magnin-Robert, M.; Randoux, B.; Tisserant, B.; Krier, F.; Jacques, P.; Reignault, P.; Halama, P. Biocontrol of the wheat pathogen Zymoseptoria tritici using cyclic lipopeptides from Bacillus subtilis. Environ. Sci. Pollut. Res. 2018, 25, 29822-29833. [CrossRef]

40. Toral, L.; Rodríguez, M.; Béjar, V.; Sampedro, I. Antifungal activity of lipopeptides from Bacillus XT1 CECT 8661 against Botrytis cinerea. Front. Microbiol. 2018, 9, 1315. [CrossRef]

41. Han, Y.; Li, X.; Guo, Y.; Sun, W.; Zhang, Q. Co-production of multiple antimicrobial compounds by Bacillus amyloliquefaciens WY047, a strain with broad-spectrum activity. Trans. Tianjin Univ. 2018, 24, 160-171. [CrossRef]

42. Arguelles-Arias, A.; Ongena, M.; Halimi, B.; Lara, Y.; Brans, A.; Joris, B.; Fickers, P. Bacillus amyloliquefaciens GA1 as a source of potent antibiotics and other secondary metabolites for biocontrol of plant pathogens. Microb. Cell Fact. 2009, 8, 63. [CrossRef]

43. De Filippi, S.; Groulx, E.; Megalla, M.; Mohamed, R.; Avis, T.J. Fungal competitors affect production of antimicrobial lipopeptides in Bacillus subtilis strain B9-5. J. Chem. Ecol. 2018, 44, 374-383. [CrossRef]

44. Adeniji, A.A.; Aremu, O.S.; Babalola, O.O. Selecting lipopeptide-producing, Fusarium-suppressing Bacillus spp.: Metabolomic and genomic probing of Bacillus velezensis NWUMFkBS10.5. Microbiol. Open 2018, 8, e742. [CrossRef]

45. Luo, C.; Liu, X.; Zhou, H.; Wang, X.; Chen, Z. Nonribosomal peptide synthase gene clusters for lipopeptide biosynthesis in Bacillus subtilis 916 and their phenotypic functions. Appl. Environ. Microbiol. 2015, 81, 422-431. [CrossRef] [PubMed] 
46. Pajčin, I.; Grahovac, J.; Dodić, J.; Vlajkov, V.; Dodić, S.; Jokić, A.; Grahovac, M. Biocontrol of Xanthomonas spp. by Bacillus velezensis cultivated on commercial and raw glycerol. In Proceedings of the 4th International Symposium on Biological Control of Bacterial Plant Diseases (Biocontrol 2019), Viterbo, Italy, 9-11 July 2019.

47. Sanchez, S.; Demain, A.L. Metabolic regulation of fermentation processes. Enzym. Microb. Technol. 2002, 31, 895-906. [CrossRef]

48. Rončević, Z.; Pajčin, I.; Cvetković, D.; Dodić, S.; Grahovac, J.; Dodić, J. Optimization of cultivation medium composition for production of bioactive compounds effective against Penicillium sp. Pestic. Phytomed. 2018, 33, 27-37. [CrossRef]

49. Ngatia, L.; Taylor, R. Phosphorus eutrophication and mitigation strategies. In Phosphorus—Recovery and Recycling; Zhang, T., Ed.; InTech Open: London, UK, 2018; pp. 45-61. [CrossRef]

50. Patel, H.; Tscheka, C.; Edwards, K.; Karlsson, G.; Heerklotz, H. All-or-none membrane permeabilization by fengycin-type lipopeptides from Bacillus subtilis QST713. Biochim. Biophys. Acta 2011, 1808, 2000-2008. [CrossRef]

51. Medeot, D.B.; Fernandez, M.; Morales, G.M.; Jofré, E. Fengycins from Bacillus amyloliquefaciens MEP218 exhibit antibacterial activity by producing alterations on the cell surface of the pathogens Xanthomonas axonopodis pv. vesicatoria and Pseudomonas aeruginosa PA01. Front. Microbiol. 2020, 10, 3107. [CrossRef] [PubMed]

52. Zhao, X.; Kuipers, O.P. Identification and classification of known and putative antimicrobial compounds produced by a wide variety of Bacillales species. BMC Genom. 2016, 17, 882. [CrossRef] [PubMed]

53. Chen, L.; Heng, J.; Qin, S.; Bian, K. A comprehensive understanding of the biocontrol potential of Bacillus velezensis LM2303 against Fusarium head blight. PLoS ONE 2018, 13, e0198560. [CrossRef]

54. Cheffi, M.; Gharbi, Y.; Medhioub, I.; Ennouri, K.; Barham, H.; Tounsi, S.; Triki, M.A. The endophytic strain Bacillus velezensis OEE1: An efficient biocontrol agent against Verticillium Wilt of Olive and a potential plant growth promoting bacteria. Biol. Control 2019, 142, 104168. [CrossRef]

55. Dhouib, H.; Zouari, I.; Abdallah, D.B.; Belbahri, D.; Taktak, W.; Triki, M.A.; Tounsi, S. Potential of a novel endophytic Bacillus velezensis in tomato growth promotion and protection against Verticillium wilt disease. Biol. Control 2019, 139, 104092. [CrossRef]

56. Rabbee, M.F.; Ali, M.S.; Choi, J.; Hwang, B.S.; Jeong, S.C.; Baek, K. Bacillus velezensis: A valuable member of bioactive molecules within plant microbiomes. Molecules 2019, 24, 1046. [CrossRef] 